\title{
Market Efficiency, the Pareto Wealth Distribution, and the Lévy Distribution of Stock Returns
}

\author{
Moshe Levy*
}

October 2001

*The Jerusalem School of Business Administration at The Hebrew University of Jerusalem, Jerusalem, Israel, 91905. mslm@mscc.huji.ac.il. Tel: 9722588 3219. Fax: 97225881341. I am grateful to Tony Bernardo, Michael Brennan, Haim Levy, Victor Ríos-Rull, Richard Roll, Eduardo Schwartz, Joel Slemrod, Sorin Solomon, and Ed Wolff for their helpful comments and suggestions. This study has been financially supported by the Zagagi Fund. 


\title{
Market Efficiency, the Pareto Wealth Distribution, and the Lévy Distribution of Stock Returns
}

\begin{abstract}
The Pareto (power-law) wealth distribution, which is empirically observed in many countries, implies rather extreme wealth inequality. For instance, in the U.S. the top $1 \%$ of the population holds about $40 \%$ of the total wealth. What is the source of this inequality? The answer to this question has profound political, social, and philosophical implications. We show that the Pareto wealth distribution is a robust consequence of a fundamental property of the capital investment process: it is a stochastic multiplicative process. Moreover, the Pareto distribution implies that inequality is driven primarily by chance, rather than by differential investment ability. This result is closely related to the concept of market efficiency, and may have direct implications regarding the economic role and social desirability of wealth inequality. We also show that the Pareto wealth distribution may explain the Lévy distribution of stock returns, which has puzzled researchers for many years. Thus, the Pareto wealth distribution, market efficiency, and the Lévy distribution of stock returns are all closely linked.
\end{abstract}

Keywords: wealth distribution, inequality, Pareto, market efficiency, distribution of stock returns.

JEL Classification: D31, E44, G10. 


\section{Introduction}

In this study we focus on three seemingly unrelated issues: a) the distribution of wealth and wealth inequality, b) market efficiency: do some investors have stock selection or market "timing" ability, or is success and failure in capital investments primarily due to chance? c) the distribution of stock returns, and in particular, the "fat tailed" Lévy distribution observed by Mandelbrot [1963], and recently precisely measured by Mantegna and Stanley [1995] and others. We show in this paper that although it seems that these are three unrelated research topics (the first in economics, and the other two in finance), they are, in fact, very closely related.

The Pareto wealth distribution is shown to be a robust consequence of the stochastic multiplicative nature of the investment process. However, we find that the Pareto distribution can occur only if the market is efficient - which implies that success and failure in investments is primarily due to chance. Thus, it is chance, rather than differential investment ability, which drives the Pareto wealth distribution and the rather extreme inequality which it implies. Furthermore, the Pareto wealth distribution can explain the (truncated) Lévy distribution of stock returns. The mechanism we suggest implies a surprising and empirically testable prediction: the exponent of the Lévy return distribution should be equal to the Pareto constant. Cross-country empirical investigation reveals striking agreement between these two a-priori unrelated parameters: U.S.: $\alpha_{\mathrm{L}}=1.37, \alpha_{\mathrm{w}}=1.35$; U.K.: $\alpha_{\mathrm{L}}=1.08, \alpha_{\mathrm{w}}=1.06$; France: $\alpha_{L}=1.82, \alpha_{w}=1.83$, where $\alpha_{L}$ is the Lévy characteristic exponent and $\alpha_{w}$ is the Pareto constant. Thus, the Pareto wealth distribution, market efficiency, and the Lévy distribution of stock returns, are all tightly linked. 
When examining the wealth distribution in society one typically finds two distinct regions. At the lower-wealth range the distribution of wealth can be approximated by the log-normal distribution. At the high-wealth range the distribution is described by the Pareto distribution (see, for example, Stiendl [1965]). In this paper we focus on the Pareto distribution which characterizes the high-wealth range. This range is extremely important because, although it accounts for a relatively small part of the population (typically about $5 \%$ ), it accounts for most of the wealth 1 . In addition, when considering wealth accumulation through capital investments, it is the high-wealth range which is relevant to the analysis.

A century ago Pareto [1897] discovered that at the high wealth range, wealth (and also income) are distributed according to a power-law distribution. The parameters of this distribution may change across societies, but regardless of the social or political conditions, taxation, etc., Pareto claimed that the wealth distribution obeys this general distribution law, which became known as the Pareto distribution or Pareto law. The Pareto distribution is given by the following probability density function:

\footnotetext{
${ }^{1}$ According to Wolff [1995] the top $1 \%$ of the population in the U.S. holds more than $40 \%$ of the total wealth. Díaz-Giménez, Quadrini, and Ríos-Rull [1997] report that the top 5\% of the population holds $55 \%$ of the wealth.

${ }^{2}$ Several researchers employ neoclassical growth models with uninsurable idiosyncratic earning shocks in order to explain the entire empirically observed wealth and income distributions (see Auerbach and Kotlikoff [1987], Aiyagari [1994], Ríos-Rull [1995], Huggett [1996], Krusell and Smith [1996], and Castaneda, Díaz-Giménez and Ríos-Rull [1997] ). This is a formidable task as it aims to explain the distribution both at the high-wealth range and the low-wealth range with a single model. This is difficult because the main factors influencing the wealth of a person at the lower range are usually labor income and consumption, while the wealth of individuals in the high-wealth range typically changes mainly due to capital investments. Indeed, as Quadrini and Ríos-Rull [1997] report, these models typically produce distributions of wealth which differ significantly from the empirical U.S. wealth distribution. Regarding the fit of income distributions to the Pareto distribution Blinder [1974] asserts:

"It may well be no accident that the upper tails of almost all income distributions, where returns to capital dominate and earnings play a minor role, exhibit a striking resemblance to the Pareto distribution" (pp. 7-8).

Here we focus only on capital investments and on the high-wealth range.
} 


$$
\mathrm{P}(\mathrm{W})=\mathrm{CW}^{-(1+\alpha)} \quad \text { for } \mathrm{W} \geq \mathrm{W}_{0}
$$

where $\mathrm{W}$ stands for wealth, $\mathrm{P}(\mathrm{W})$ is the density function, $\mathrm{W}_{0}$ is the lower end of the high wealth range, and $\mathrm{C}$ is a normalization constant, and $\alpha$ is known as the Pareto constant.

Pareto's finding has been shown in numerous studies to provide an excellent fit to the empirical wealth distribution in various countries (see, for example, Steindl [1965], Atkinson and Harrison [1978], Persky [1992], Levy and Solomon [1997]). Several researchers claim that the Pareto law is very universal. Davis [1941] argues that:

No one however, has yet exhibited a stable social order, ancient or modern, which has not followed the Pareto pattern at least approximately. (p. 395) Snyder [1939] writes:

Pareto's curve is destined to take its place as one of the great generalizations of human knowledge

Several examples of the fit of the Pareto law to the empirical wealth distribution are provided by Figures 8-10, which depict the wealth distribution in France, the U.K. and the U.S. These figures are discussed in detail in section 5.

The first to suggest an explanation for the Pareto distribution of wealth was Pareto himself (Pareto [1906]). Pareto suggested that the distribution of wealth corresponds to an underlying distribution of human abilities. However, Pareto has not offered a mathematical model that would explain the distribution of abilities and its relation to the Pareto law. Pareto's explanation was advanced by Davis who introduced the "law of the distribution of special abilities" which asserts that the probability of an additional unit of ability was independent of the level of ability (Davis [1941]). This model, however, leads to a normal distribution of ability and 
therefore presumably to a normal, rather than Pareto, distribution of wealth. A different model for the distribution of ability was formulated by Boissevain [1939] who considered the distribution of abilities that could be represented as a product of several factors, each of which follows a binomial distribution. Boissevain's model explains the positive skewness in the distributions of wealth and income, but leads to a log-normal distribution, not the empirically observed Pareto distribution.

The main models that offer an explanation for the precise form of the Pareto wealth distribution are the Markov chain model of Champernowne [1953], the stream model of Simon [1955] and the birth-and-death model of Wold and Whittle [1957]. Although these models are quite different from each other and make various different assumptions, in all of these models the wealth accumulation process is a stochastic multiplicative process. A stochastic multiplicative process is a process in which the value of each element is multiplied by a random variable with each time step. Many economic processes, and in particular the accumulation of wealth via investment of capital, are stochastic and multiplicative by nature. For example, if a person invests her money in a portfolio which yields $10 \%$ with probability $1 / 2$ and $-5 \%$ with probability $1 / 2$ each year, her wealth will follow a stochastic multiplicative process. The main difference between multiplicative and additive processes is that in additive processes (such as random walks) the changes in value are independent of the value, whereas in multiplicative processes the changes are proportional to the value.

In this paper we argue that the multiplicative nature of the capital investment process is the reason for the empirically observed Pareto wealth distribution. Indeed, starting with an arbitrary non-degenerate initial wealth distribution, any process which

\footnotetext{
${ }^{3}$ For a review of models generating Pareto distributions see Steindl [1965], Arnold [1983], and Slottje [1989].
} 
is stochastically multiplicative and homogeneous leads to the Pareto law. The homogeneity of the process in essence means that individuals do not posses 
differential investment abilities and cannot "beat the market". This idea is closely related to the concept of market efficiency: in an efficient market one would not expect to find investors who consistently outperform their peers. We show that non-homogeneous multiplicative processes lead to a wealth distribution which is different from the Pareto distribution. Thus, the Pareto distribution implies market efficiency. Our analysis leads us to conclude that the extreme inequality in modern western society is a very fundamental and robust outcome of the nature of the capital investment process. Furthermore, this inequality is driven primarily by chance, rather than by differential ability.

The structure of this paper is as follows. In section 2 we present the framework of stochastically multiplicative investment processes. We prove that homogeneous processes lead to the Pareto wealth distribution, and to the extreme inequality which it implies. In section 3 we discuss non-homogeneous processes and show that they lead to wealth distributions different than the Pareto distribution. This section reveals that the Pareto distribution is closely related to market efficiency, and puts an upper bound on the degree of market inefficiency. In section 4 we show that the Lévy distribution of stock returns can be explained by the Pareto wealth distribution. The theoretical prediction resulting from this analysis is empirically tested in section5. Section 6 concludes.

\section{Stochastic Multiplicative Processes}

A stochastic multiplicative wealth accumulation process is given by:

$$
\mathrm{W}_{\mathrm{i}}^{\mathrm{t}+1}=\mathrm{W}_{\mathrm{i}}^{\mathrm{t}} \tilde{\lambda}_{\mathrm{i}}^{\mathrm{t}}
$$

where $\mathrm{W}_{\mathrm{i}}^{\mathrm{t}}$ is the wealth of investor $\mathrm{i}$ at time $\mathrm{t}$ and $\tilde{\lambda}_{\mathrm{i}}^{\mathrm{t}}$ represents the stochastic return, which is a random variable drawn from some distribution $\mathrm{g}_{\mathrm{i}}(\tilde{\lambda})$. Generally, each investor may have a different distribution of returns on his investment, hence the sub-index $i$ in $g_{i}(\tilde{\lambda})$. 
For people at the high-wealth range, changes in wealth are mainly due to financial investment, and are therefore typically multiplicative. For people at the lower wealth range, changes in wealth are mainly due to labor income and consumption, which are basically additive rather than multiplicative. Here we are only interested in modeling wealth dynamics in the high-wealth range. There are many ways one could model the boundary between these two regions. We start by considering the most simple model in which there is a sharp boundary between the two regions. The specific modeling of the boundary does not change our general results. As the stochastic multiplicative process (eq.(2)) describes the dynamics only at the higher wealth range, we introduce a threshold wealth level, $\mathrm{W}_{0}$, above which the dynamics are multiplicative. We assume that only those people with wealth exceeding $\mathrm{W}_{0}$ participate in the stochastic multiplicative investment process. Formally, we require that:

$$
\mathrm{W}_{\mathrm{i}}^{\mathrm{t}} \geq \mathrm{W}_{0} \quad \text { for all } \mathrm{i} \text {, and for all } \mathrm{t} \text {. }
$$

In the case that there is an overall drift towards lower wealth values (as in Champernowne [1953]) one can define the lower bound $\mathrm{W}_{0}$ in absolute terms. In general, however, we would expect the drift to be towards higher wealth values (as when there is inflation or a growing economy, for example). In this case, an absolute lower bound value becomes meaningless, and one has to define the lower bound in real terms. A natural way to define the lower bound is in terms of the average wealth. We define the lower bound, $\mathrm{W}_{0}$, as $\mathrm{W}_{0}=\omega \frac{1}{\mathrm{~N}} \sum_{\mathrm{i}=1}^{\mathrm{N}} \mathrm{W}_{\mathrm{i}}^{\mathrm{t}}$, where $\mathrm{N}$ is the number of investors and $\omega$ is a threshold given in absolute terms $(\omega<1)$.

As people's wealth changes, they may cross the boundary between the upper and lower wealth regions. We do not model the dynamics at the lower wealth range, 
and for the sake of simplicity, we assume that the market has reached an equilibrium in which the flow of people across the boundary is equal in both directions, i.e. the number of people participating at the stochastic multiplicative investment process remains constant. The above assumption simplifies the analysis, but the results presented here are robust to the relaxation of this assumption.

In a homogeneous process all investors face the same return distribution i.e. :

$$
\mathrm{W}_{\mathrm{i}}^{\mathrm{t}+1}=\mathrm{W}_{\mathrm{i}}^{\mathrm{t}} \tilde{\lambda}_{\mathrm{i}}^{\mathrm{t}}, \mathrm{W}_{\mathrm{i}}^{\mathrm{t}} \geq \mathrm{W}_{0}, \quad \text { and } \mathrm{g}_{\mathrm{i}}(\tilde{\lambda})=\mathrm{g}(\tilde{\lambda}) \text { for all investors } \mathrm{i} \text {. }
$$

Note that although all investors face the same return distribution $\mathrm{g}(\tilde{\lambda}), \tilde{\lambda}$ is drawn separately for each investor. One way to think of this, is to think of investors who have the same objective but have different expectations, and therefore hold different portfolios. At each period every investor will have a different realized return, but if all investors have the same stock-picking and market-timing abilities, none of them achieves a return distribution better than the others', and they draw their returns from the same distribution (see also footnote 8). A "lucky" investor is one for which many high values of $\lambda$ are drawn. Such a lucky investor will become richer than others. Note that in the homogeneous case investors face the same distribution of returns, and thus the differentiation in wealth is entirely due to chance.

The next theorem shows that the Pareto wealth distribution is a very robust result of homogeneous multiplicative processes.

\section{$\underline{\text { Theorem } 1}$}

For any initial wealth distribution and non-trivial return distribution $(\operatorname{Var}(\lambda)>0)$, the wealth accumulation process given by eq.(4) leads to a convergence of the wealth distribution to the Pareto distribution. 


\section{Proof:}

Denote the cumulative wealth distribution at time $t$ and at time $t+1$ by $F(W, t)$ and $F(W, t+1)$, respectively. Then, because the wealth of the $i^{\text {th }}$ investor changes from $\mathrm{W}_{\mathrm{i}}^{\mathrm{t}}$ at time $\mathrm{t}$ to $\mathrm{W}_{\mathrm{i}}^{\mathrm{t}} \tilde{\lambda}_{\mathrm{i}}^{\mathrm{t}}$ at time $\mathrm{t}+1$, i.e. $\mathrm{W}_{\mathrm{i}}^{\mathrm{t}+1}=\mathrm{W}_{\mathrm{i}}^{\mathrm{t}} \tilde{\lambda}_{\mathrm{i}}^{\mathrm{t}}$ (see eq.(1)), the cumulative wealth distribution at $\mathrm{t}+1$ is given by:

$$
\mathrm{F}(\mathrm{W}, \mathrm{t}+1)=\int_{0}^{+\infty} \mathrm{F}\left(\frac{\mathrm{W}}{\lambda}, \mathrm{t}\right) \mathrm{g}(\lambda) \mathrm{d} \lambda
$$

where all values of $\lambda$ such that the wealth at $t+1$ is equal to $\frac{\mathrm{W}}{\lambda} \lambda=\mathrm{W}$ are accounted for ${ }^{7}$.

Equation (5) describes a process in which the probability $\mathrm{F}(\mathrm{W})$ at time $\mathrm{t}+1$ is a weighted average of the probability at points surrounding $\mathrm{W}$ (points $\frac{\mathrm{W}}{\lambda}$ ) at time t. Thus, starting from an arbitrary probability density, $\mathrm{F}(\mathrm{W}, 0)$, the distribution $\mathrm{F}(\mathrm{W})$ undergoes a continuous "smoothing" process. In the presence of an effective lower bound on wealth $\left(\mathrm{W}_{\mathrm{i}}^{\mathrm{t}} \geq \mathrm{W}_{0}\right)$, this smoothing process is analogues to diffusion towards a barrier (see Levy and Solomon [1996]). Such a process is well-known to lead to the convergence of $\mathrm{F}(\mathrm{W})$ to a stationary distribution (Boltzmann [1964], Feynman, Leighton, and Sands [1964]). For the limiting stationary wealth distribution we have $\mathrm{F}(\mathrm{W}, \mathrm{t}+1)=\mathrm{F}(\mathrm{W}, \mathrm{t})=\mathrm{F}(\mathrm{W})$ and eq.(5) becomes:

$$
\mathrm{F}(\mathrm{W})=\int_{0}^{+\infty} \mathrm{F}\left(\frac{\mathrm{W}}{\lambda}\right) \mathrm{g}(\lambda) \mathrm{d} \lambda
$$

Differentiating with respect to $\mathrm{W}$ we obtain the density function:

\footnotetext{
${ }^{4}$ As $\tilde{\lambda}$ represents the total return on capital investment, it can not be less than 0 (which corresponds to a rate of return of $-100 \%)$.
} 


$$
f(W)=\int_{0}^{+\infty} f\left(\frac{W}{\lambda}\right) \frac{1}{\lambda} g(\lambda) d \lambda
$$

In order to show that the Pareto distribution is a solution to eq.(7), substitute the Pareto probability density function (eq.(1)) for $\mathrm{f}(\mathrm{W})$ in eq.(7) to obtain:

$$
\frac{\alpha \mathrm{k}^{\alpha}}{\mathrm{W}^{\alpha+1}}=\int_{0}^{+\infty} \frac{\alpha \mathrm{k}^{\alpha}}{(\mathrm{W} / \lambda)^{\alpha+1}} \frac{1}{\lambda} \mathrm{g}(\lambda) \mathrm{d} \lambda=\frac{\alpha \mathrm{k}^{\alpha}}{\mathrm{W}^{\alpha+1}} \int_{0}^{+\infty} \lambda^{\alpha} \mathrm{g}(\lambda) \mathrm{d} \lambda .
$$

Thus, it is evident that the Pareto distribution with $\alpha$ satisfying $\int_{0}^{+\infty} \lambda^{\alpha} g(\lambda) \mathrm{d} \lambda=1$ is a solution to eq(6). The Pareto distribution is also the unique positive solution to (6) because the only positive $g$-harmonic functions on $\mathfrak{R}$ are exponentials (see Choquet [1960], Loomis [1962], and Furstenberg [1965], Theorem B, p.291).

Theorem 1 shows that the Pareto distribution is a limit distribution of homogeneous stochastic multiplicative wealth accumulation processes, as given by eq.(4). We would like to emphasize that the analysis is quite general and does not rely on any specific form of the return distribution $g(\lambda)$, as long as this distribution is non-trivial.

Monte Carlo simulations of the homogeneous multiplicative wealth accumulation process illustrate the result of Theorem 1, and provide an estimate of the time it takes the wealth distribution to converge to the Pareto distribution. We have conducted simulations in which all investors start out with an identical initial wealth level of $\$ 100,000$. The return distribution $\mathrm{g}(\tilde{\lambda})$ is taken as:

\footnotetext{
${ }^{5}$ Notice that the results of Champernowne [1953] and Wold and Whittle [1957] can be viewed as special cases of Theorem 1. The theorem is also closely related to Kesten [1973] who investigates processes of the type $\mathrm{x}_{\mathrm{i}}^{\mathrm{t}+1}=\mathrm{x}_{\mathrm{i}}^{\mathrm{t}} \tilde{\lambda}_{i}{ }^{\mathrm{t}}+\widetilde{\varepsilon}_{\mathrm{i}}^{\mathrm{t}}$, which are similar to eq.(1), with the additive random variable $\tilde{\varepsilon}_{i}^{t}$ replacing the role of the lower bound. Recently, Gabaix [1999] employs similar arguments to explain Zipf's [1949] Law for the distribution of city sizes.
} 
probability

$\begin{array}{ll}1.10 & 1 / 2 \\ 0.95 & 1 / 2\end{array}$

i.e. at every time period each investor has an equal probability to gain $10 \%$ or to lose $5 \%$. The lower wealth bound $\left(\mathrm{W}_{0}\right)$ is set to $20 \%$ of the average wealth. We have recorded the distribution of wealth at different times. The results are shown in Figure 1 , which is a two-way logarithmic plot of the probability density as a function of wealth (in units of the average wealth). The dashed vertical line at 0.2 represents the minimal wealth threshold $\mathrm{W}_{0}$. Note that the theoretical Pareto distribution (eq.(1)) is a power-law distribution, and it is therefore linear when plotted on a double-logarithmic scale. ${ }^{\text {G }}$ The distribution after 10 investment periods (Figure 1a) is still rather symmetric, and centered around the average wealth (1.0 on the horizontal axis). However, after 100 time periods the wealth distribution is very close to the Pareto distribution (Figure 1b). The distribution remains Paretian from then on ${ }^{\text {] }}$ Figure 1c shows the wealth distribution after 10,000 time periods.

\section{(Insert Figure 1 About Here)}

The homogeneity of the process $\left(g_{i}(\lambda)=g(\lambda)\right.$ for all i) implies an efficient market: no investor is able to achieve a superior distribution of returns which dominates $g(\lambda)$. In the next section we show that this is indeed a necessary condition for the emergence of a Pareto distribution ${ }^{\text {B }}$. If the market is inefficient and

\footnotetext{
${ }^{6}$ Take the logarithm of both sides of eq.(1) to obtain: $\log [\mathrm{P}(\mathrm{W})]=\log [\mathrm{C}]-(1-\alpha) \log [\mathrm{W}]$.

${ }^{7}$ The slope of the line in Figures $2 b$ and $2 \mathrm{c}$ is -2.25 , which implies $1+\alpha=2.25$ or $\alpha=1.25$. This value is typical of western countries, and it is between the value of $\alpha$ in the U.K. (1.06) and the value of $\alpha$ in the U.S. (1.35), (see section 5).

${ }^{8}$ Market efficiency is necessary, but not sufficient. Even if all investors have similar investment talent they may still have different distributions of returns, due to different attitudes towards risk. However, if investors have long horizons (which seems reasonable for the high-wealth range), then under mild assumptions regarding preferences, they should all seek to find the investment which maximizes the geometric mean (see Latané [1959], Markowitz [1976], and Leshno and Levy [1997]). If this is the case, they have the same goal, and in an efficient market they are likely to draw returns from similar distributions.
} 
$\mathrm{g}_{\mathrm{i}}(\lambda) \neq \mathrm{g}_{\mathrm{j}}(\lambda)$ a wealth distribution which is different than the Pareto distribution emerges.

\section{Non-Homogeneous Multiplicative Processes and Market Efficiency}

As a first step toward the analysis of the general heterogeneous model $\left(g_{\mathrm{i}}(\lambda) \neq \mathrm{g}_{\mathrm{j}}(\lambda)\right)$, we analyze the case of two sub-populations. Consider a market in which some of the population has "normal" investment skills and faces the return distribution $\mathrm{g}_{\text {normal }}(\tilde{\lambda})$, while a minority of "smart" investors are able to take advantage of market inefficiencies and to obtain the superior distribution $\mathrm{g}_{\text {smart }}(\tilde{\lambda})$, such that $\sigma\left(\mathrm{g}_{\text {smart }}\right)=\sigma\left(\mathrm{g}_{\text {normal }}\right)$ and $\mathrm{E}\left(\mathrm{g}_{\text {smart }}\right)>\mathrm{E}\left(\mathrm{g}_{\text {normal }}\right)$. The resulting wealth distribution will be different from the Pareto distribution, as the Theorem below shows.

Theorem 2:

In the case of two different sub-populations, as described above, the wealth distribution converges to a distribution which does not conform with the Pareto Law. Proof:

Over time the "smart" investors become on average richer than the "normal" investors. As the "normal" investors become relatively poorer, more and more of them will cross the lower wealth threshold, $\mathrm{W}_{0}$, and will exit the market. One might suspect that in the long run the "normal" population will be completely wiped out. However, recall that there is an inflow of investors into the market. This is an inflow of investors from below the threshold who have acquired enough wealth in order to participate in the investment process. (We do not model the process of wealth accumulation below the threshold, but assume that the market is in a steady state in which the inflow of new investors balances the outflow of investors leaving the market. This assumption simplifies the analysis but is not essential to our results.) 
Some of the new investors entering the market are of the "normal" type As the number of "normal" investors declines, so does their proportion in the outflow from the market. Eventually, a balance is reached when the outflow of investors of each type matches the inflow of that type, and the size of each subgroup converges to a certain (mean) value.

As the population of each subgroup is homogeneous, the wealth distribution of each subgroup is subject to the dynamics described by equation (4)! $\frac{10}{6}$ From the result of Theorem 1 it follows that the wealth of each subgroup will be divided between the members of that subgroup according to the Pareto distribution. Thus, the wealth distribution among "normal" investors is:

$$
\mathrm{P}_{\text {normal }}(\mathrm{W})=\mathrm{C}_{\text {normal }} \mathrm{W}^{-\left(1+\alpha_{\text {normal }}\right)}
$$

and the wealth distribution among "smart" investors is:

$$
\mathrm{P}_{\text {smart }}(\mathrm{W})=\mathrm{C}_{\text {smart }} \mathrm{W}^{-\left(1+\alpha_{\text {smart }}\right)} \quad
$$

Both distributions are Paretian, but with different parameters $C$ and $\alpha$. As the average wealth of the smart population is greater than the average wealth of the normal

\footnotetext{
${ }^{9}$ One can think of different ways in which to compose the population of new investors: a) for each investor exiting the market an investor of the same type enters. b) each new investor has a certain probability p for being "smart" and probability (1-p) of being "normal". The choice between the above two alternatives, and the value of the probability $\mathrm{p}$, may change the specific parameters of the steady state wealth distribution, but not it's essential features, as described below.

${ }^{10}$ The interaction between the different subgroups is only through the lower bound $\mathrm{W}_{0}$, which depends on the average wealth of all investors in the market.
} 
population, we will have $\alpha_{\text {smart }}<\alpha_{\text {normal }} \cdot$ The aggregate distribution of wealth is given by:

$$
\mathrm{P}(\mathrm{W})=\mathrm{C}_{1} \mathrm{~W}^{-\left(1+\alpha_{\text {normal }}\right)}+\mathrm{C}_{2} \mathrm{~W}^{-\left(1+\alpha_{\text {smart }}\right)} \text {, }
$$

which is not a Pareto distribution $\frac{12 \cdot 13}{\text {. E.D. }}$ Q.E.

The result of Theorem 2 can be directly generalized to the case of many sub-populations: in this case the wealth distribution within each sub-population follows the Pareto Law, but as each sub-population is characterized by a different parameter $\alpha$, the aggregate distribution is not Paretian.

Monte Carlo simulations can help illustrate the result of Theorem 2, and confirm that this result holds for the general case of many sub-populations. Figure 2 shows the wealth distribution in the two-population case, where the "normal"

\footnotetext{
${ }^{11}$ The lower the value of the exponent $\alpha$ of the Pareto distribution, the higher the average wealth. $-\alpha$ is the slope of the distribution function on the double-logarithmic scale. It is therefore intuitively clear that the more moderate the slope (smaller $\alpha$ ) the more weight is given to higher wealth states.
} Formally:

$$
\mathrm{E}(\mathrm{W})=\int_{\mathrm{W}_{0}}^{+\infty} \mathrm{P}(\mathrm{W}) \mathrm{WdW}=\mathrm{C} \int_{\mathrm{W}_{0}}^{+\infty} \mathrm{W}^{-(1+\alpha)} \mathrm{WdW}=\frac{\mathrm{C}}{(\alpha-1)} \mathrm{W}_{0}^{1-\alpha} .
$$

(We assume $\alpha>1$, otherwise $\mathrm{E}(\mathrm{W})$ is infinite. Empirical values of $\alpha$ are typically in the range 1.2-1.6). From the normalization condition $\int_{\mathrm{W}_{0}}^{+\infty} \mathrm{P}(\mathrm{W}) \mathrm{dW}=1$ we obtain $\mathrm{C}=\alpha \mathrm{W}_{0}^{\alpha}$. Substituting in the above equation we obtain :

$$
\mathrm{E}(\mathrm{W})=\mathrm{W}_{0} \frac{\alpha}{(\alpha-1)},
$$

which is a monotonically decreasing function of $\alpha$.

${ }^{12} \mathrm{C}_{1}$ and $\mathrm{C}_{2}$ replace $\mathrm{C}_{\text {normal }}$ and $\mathrm{C}_{\text {smart }}$ because the normalization constraints have changed, and depend on the relative proportions of the two subgroups, i.e.: $\mathrm{C}_{1}=\frac{\mathrm{N}_{\text {normal }}}{\mathrm{N}} \mathrm{C}_{\text {normal }}$; $\mathrm{C}_{2}=\frac{\mathrm{N}_{\text {smart }}}{\mathrm{N}} \mathrm{C}_{\text {smart }}$.

\footnotetext{
${ }^{13}$ The wealth distribution given in eq.(11) is asymptotically Paretian, i.e. as $\mathrm{W} \rightarrow \infty$ $\mathrm{P}(\mathrm{W}) \approx \mathrm{C}_{2} \mathrm{~W}^{-\left(1+\alpha_{\text {smart }}\right)}$. Thus, it is approximately Paretian in the wealth range where the investor population is homogeneous (in the range where all the investors are "smart"). Hence, if we empirically observe that the wealth distribution is closely approximated by the Pareto distribution for the top 5\% of the population, we may conclude that among these top 5\% investment ability is homogeneous.
} 
population faces the return process:

$\begin{array}{llc} & \underline{\lambda} & \text { probability } \\ \mathrm{g}_{\text {normal }}(\tilde{\lambda}): & 1.10 & 1 / 2 \\ & 0.95 & 1 / 2\end{array}$

while the "smart" investors face the following superior return process:

$\begin{array}{ccc} & \underline{\lambda} & \text { probability } \\ \mathrm{g}_{\text {smart }}(\tilde{\lambda}): & 1.11 & 1 / 2 \\ & 0.96 & 1 / 2\end{array}$

Figure 2 shows that although the distribution of wealth within each sub-population follows the Pareto law $\left(\alpha_{\text {normal }}=1.67, \alpha_{\text {smart }}=0.63\right)$, the aggregate distribution (solid line) does not. This is evident from the convexity of the aggregate distribution, while a Pareto distribution should be linear on a double-logarithmic scale (see footnote 6). The same convex pattern, which contradicts the Pareto distribution, is also obtained in the general case with many investor sub-populations. Figure 3 depicts the steady-state wealth distribution in a market in which each investor faces a different return distribution. For all investors the return distribution $g_{i}(\tilde{\lambda})$ is taken as a normal distribution with a standard deviation of $20 \%$. However, the mean of the distribution $g_{i}(\tilde{\lambda}), \mu_{i}$, is different for each investor. We assume that $\mu$ is distributed normally in the population with a mean value of $10 \%$ and a standard deviation of $2 \%$. Even though the distribution of talent is rather narrow (for $85 \%$ of the investors $\mu_{i}$ is in the range $8 \%-12 \%$ ), the resulting distribution of wealth is clearly different than the Pareto distribution (see Figure 3). The Kolmogorov-Smirnov goodness-of-fit test confirms that one can safely reject the hypothesis that the generated distribution is Paretian. Comparing the cumulative distributions of the sample distribution with the best fit Pareto distribution (with 1000 investors) we obtain a $\mathrm{D}$ value of 0.310 , which 
is much larger than the critical D value of $0.052(=1.63 / \sqrt{1000})$ needed in order to reject the hypothesis that the distribution is Paretian at a $99 \%$ confidence level.

(Insert Figures 2 and 3 About Here)

While the Pareto wealth distribution cannot precisely hold in an inefficient market with differential investment ability, it can be consistent with some degree of market inefficiency (and differential investment ability) in the sense that the Pareto distribution cannot be statistically rejected. Levy and Levy [2001] employ numerical analysis to show that the Pareto distribution cannot be statistically rejected if the annual average return across different investor subgroups is within approximately $1 \%$. Thus, the empirically observed wealth distribution, which is very close to a Pareto distribution, does not imply a perfectly efficient market, but it does impose a rather tight upper bound on market inefficiency.

\section{The Pareto Wealth distribution and the Lévy distribution of Stock Returns}

In this section we suggest that the Pareto wealth distribution can explain the Lévy distribution of short-term stock returns. We proceed with a brief review of the distribution of short-term stock returns. Our theoretical result regarding the distribution of stock returns and its relation to the wealth distribution is given in Theorem 3. This result has a surprising and testable prediction, which we empirically investigate in section 5 .

\subsection{The Lévy Distribution of Stock Returns - Review}

It has been long known that the distributions of returns on stocks, especially when calculated for short time intervals, are not fitted well by the normal distribution. Rather, the distributions of stock returns are leptokurtic, or "fat tailed". Mandelbrot [1963a, 1963b] proposed an exact functional form for return distributions. To be 
specific, he has suggested that log-returns are distributed according to the symmetrical Lévy probability distribution defined by:

$$
\mathrm{L}_{\alpha_{\mathrm{L}}}^{\gamma}(\mathrm{x}) \equiv \frac{1}{\pi} \int_{0}^{\infty} \exp \left(-\gamma \Delta \mathrm{tq}{ }^{\alpha_{\mathrm{L}}}\right) \cos (\mathrm{qx}) \mathrm{dq}
$$

where $L_{\alpha_{L}}^{\gamma}(x)$ is the Lévy probability density function at $x, \alpha_{L}$ is the characteristic exponent of the distribution, $\gamma \Delta \mathrm{t}$ is a general scale factor, $\gamma$ is the scale factor for $\Delta \mathrm{t}=1$, and $\mathrm{q}$ is an integration variable (for this formulation of the Lévy distribution see, for example, Mantegna and Stanley [1995] $)^{14}$.

Mandelbrot's pioneering work gained enthusiastic support in the first few years after it's publication. ${ }^{15}$ Subsequent works, however, have questioned the Lévy distribution hypothesis ( Hsu, Miller and Wichern [1974], Joyce, Brorsen and Irwin [1989]), and this hypothesis has temporarily lost favor. In the 90's the Lévy distribution hypothesis has made a dramatic comeback. Recent extensive analysis of short-term returns has shown that price differences, log-returns, and rates of return $\frac{16}{16}$ are described extremely well by a truncated Lévy distribution. This is not a sharp truncation in the usual mathematical sense, but rather, it describes a smooth fall-off of the empirical distribution from the Lévy distribution at some value, (for a general picture of the empirical short-term rate of return distribution, see Figure 5). Mantegna

\footnotetext{
${ }^{14}$ This distribution is also known as the "stable-Paretian" distribution. In order to avoid confusion, we will use only the term "Lévy distribution" throughout this paper.

${ }^{15}$ See Fama [1963a], Fama [1963b], Fama [1965a], Teichmoeller [1971], and Officer [1972]. Roll [1968] extended the analysis from stocks to Treasury Bills. Fama and Roll [1968, 1971] developed methodologies in order to estimate the parameters of the Lévy distribution. Efficient portfolio selection in a market with Lévy distributions was analyzed by Fama [1965b] and Samuelson [1967].

${ }^{16}$ Some studies examine the distribution of price differences, some of log-returns, and some of rates of return. As the focus is on short time intervals (a few seconds to a few days) all of the above are very closely related. See also the discussion in Appendix A.
} 
and Stanley [1995] analyze tick-by-tick data on the S\&P 500 index and find excellent agreement with a Lévy distribution up to six standard deviations away from the mean (in both directions). For more extreme observations, the distribution they find falls off faster than the Lévy distribution 17 . Similar results have been found in the examination of the Milan stock exchange (Mantegna [1991]), the CAC40 index (Zajdenweber [1994]), individual French stocks (Belkacem [1996]), and foreign exchange markets (Pictet and Muller [1995], Guillaume et al. [1997], and Cont, Potters and Bouchaud [1997]).

The revival of the (truncated) Lévy distribution awakens an old question: Why are returns distributed in this very specific way? Below we suggest that the answer may lie with the Pareto distribution of wealth.

\subsection{The Pareto Wealth Distribution and the Lévy Return Distribution}

The Levy distribution describes the distribution of returns in the short-term. We therefore formulate the framework of our analysis in terms of the most "atomistic" return - a single trade return. Theorem 3 below shows that if investors' wealth is distributed according to the Pareto distribution, and if the effect of an investor's trade on the stock price is proportional (in a stochastic sense) to the investor's wealth, the short-term returns will be distributed according to the Lévy distribution. The assumption of proportionality between the investor's wealth and the price impact of the investor's trade seems natural: it is intuitive that the actions of an investor with $\$ 100$ million will, on average, affect prices roughly 10 times as much as the actions of a similar investor with only $\$ 10$ million. This is also consistent with models of constant relative risk aversion, which imply that

\footnotetext{
${ }^{17}$ Several authors investigate this fall-off, and find it to be approximated by a power-law with an exponent in the range 2-5 (see Jansen and de Vries [1991], Longin [1996], Gopikrishnan, Meyer, Amaral and Stanley [1998], Stanley et al. [1999], and Cont [2001]).
} 
investors make decisions regarding proportions of their wealth (see, for example, Levy and Markowitz [1979], Samuelson [1989]), and with the finding that the price impact of a trade is roughly proportional to the volume of the trade, especially for high volume trades (see Figure 4 in Hausman, Lo and MacKinlay, [1992]). To be more specific, if investors make decisions regarding proportions of their wealth, then the volume of a trade is (stochastically) proportional to the investor's wealth. If the effect of the trade on the price is proportional to the volume of the trade (as implied by market clearance in most models, and as documented by Lo and Mackinlay), then the effect that an investor's trade has on the price is (stochastically) proportional to the investor's wealth. We should stress we do not make any assumptions regarding the investors' reason for trading: it can be due to the arrival of new information, liquidity constraints, portfolio rebalancing, etc.

Theorem 3:

If the wealth of investors is distributed according to the Pareto law with exponent $\alpha_{\mathrm{w}}$, and the effect of each investor's trade on the price is stochastically proportional to the investor's wealth, then the resulting return distribution (and price-change distribution) are given by the Lévy distribution with an exponent $\alpha_{\mathrm{L}}=\alpha_{\mathrm{W}}$.

Proof: See Appendix A.

Theorem 3 not only suggests an explanation for the Lévy distribution of returns, but it also makes a surprising prediction: the exponent of the Lévy return distribution, $\alpha_{\mathrm{L}}$, should be equal to the Pareto wealth distribution constant, $\alpha_{\mathrm{w}}$. This prediction is surprising, because these two parameters are associated with different research arenas, and seem to be a-priory unrelated. In the next section we test this prediction empirically. 


\section{Empirical Evidence}

In this section we empirically estimate and compare $\alpha_{\mathrm{L}}$ and $\alpha_{\mathrm{W}}$ for three countries: the U.S., the U.K., and France.

\subsection{Estimation of $\alpha_{L}$}

For the estimation of $\alpha_{L}$ we follow the methodology used by Mantegna and Stanley [1995]. They denote the density of the symmetric Lévy distribution eq.(12) at 0 by $\mathrm{p}_{0}$, and employ the relation below in order to estimate $\alpha_{\mathrm{L}}$ :

$$
\mathrm{p}_{0} \equiv \mathrm{L}_{\alpha_{\mathrm{L}}}^{\gamma}(0)=\frac{\Gamma\left(1 / \alpha_{\mathrm{L}}\right)}{\pi \alpha_{\mathrm{L}}(\gamma \Delta \mathrm{t})^{1 / \alpha_{\mathrm{L}}}}
$$

where $\Gamma$ is the Gamma function, $\Delta \mathrm{t}$ is the horizon for which rates of return are being calculated, and $\gamma$ is the scale factor for $\Delta t=1$ (for proof of the relation (13) see appendix B). Thus, the probability density at 0 decays as $\Delta \mathrm{t}^{-1 / \alpha_{\mathrm{L}}}$. Mantegna and Stanley estimate the density at $0, \mathrm{p}_{0}$, for various time intervals, $\Delta \mathrm{t}$. In order to estimate $\alpha_{L}$ they run the regression:

$$
\log \left[\mathrm{p}_{0}(\Delta \mathrm{t})\right]_{\mathrm{i}}=\mathrm{A}+\mathrm{B} \log [\Delta \mathrm{t}]_{\mathrm{i}}+\varepsilon_{\mathrm{i}}
$$

and estimate $\alpha_{\mathrm{L}}$ as $-\frac{1}{\hat{\mathrm{B}}}$. We employ the same technique here.

Our data sets consists of:

S\&P 500: all 1,780,752 records of the index between 1990-1995, obtained from the Chicago Mercantile Exchange.

FTSE 100: all 75,606 records of the index between January 1997 and August 1997, obtained from the Futures Industry Institute.

CAC 40: all 234,501 records of the index in 1996, obtained from the Bourse de Paris. 
Following Mantegna and Stanley, for each of these series we estimate the density $\mathrm{p}_{0}(\Delta \mathrm{t})$ by going over the entire data set and calculating the rates of return for intervals of $\Delta \mathrm{t}$. We count the number of rates of return within the range $[-0.0001,0.0001]$ and divide this number by the total number of observations, in order to get the probability of rate of return in this range 1 . Then we divide the result by the size of the range, 0.0002 , in order to get the probability density at $0, \mathrm{p}_{0}$. We repeat this procedure for different sampling time intervals $\Delta \mathrm{t}$. The values of $\mathrm{p}_{0}$ as a function of $\Delta \mathrm{t}$ are reported in Figures 4, 6, and 7. In order to obtain an estimate of $\alpha_{L}$ we employ the regression in eq.(14). For the $S \& P 500$ we obtain $\alpha_{L}=1.37$ (Figure 4). The standard error of this estimation is 0.04 , and the correlation coefficient is -0.987 . This estimated value that we find for $\alpha_{L}$ is very close to the value of 1.40 reported by Mantegna and Stanley [1995] for the S\&P 500, during the sample period 1984-89.

\section{(Insert Figure 4 About Here)}

In order to verify that the empirical rate of return distribution is indeed well fitted well by the symmetric Lévy distribution with the estimated $\alpha_{L}$ of 1.37 , we compare these two distributions in Figure 5. The empirical distribution is calculated for 1-minute rates of return, and the plot is semi-logarithmic. ${ }^{19}$ Figure 5 shows an excellent agreement between the empirical and theoretical distributions up to rates of return in the order of 0.001 (or $0.1 \%$ ), which are about six standard deviations away from the mean 20 . For more extreme returns, the empirical distribution falls off from

\footnotetext{
${ }^{18}$ Similar estimations of $\alpha_{\mathrm{L}}$ are obtained for different choices of small ranges around 0.

${ }^{19}$ The empirical distribution is estimated by a non-parametric density estimate with a Gaussian/ kernel and the "normal reference rule," (see Scott [1992], p. 131).

${ }^{20}$ The standard deviation of the 1-minute rate of return distribution for the period 1990-1995 is approximately 0.00016 or $0.016 \%$.
} 
the Lévy distribution. This is the so-called truncation, which will be discussed below 21 .

\section{(Insert Figure 5 About Here)}

For the FTSE 100 we find $\alpha_{\mathrm{L}}=1.08$ (Figure 6). The standard error of this estimation is 0.03 , the correlation coefficient is -0.996 , and the $t$-value is -59.7 . This number is close to the $\alpha_{\mathrm{L}}$ value of 1.10 which is calculated from the 1993 FTSE 100 data reported by Abhyankar, Copeland, and Wong [1995].

For the CAC 40 we find $\alpha_{\mathrm{L}}=1.82$ (Figure 7). The standard error of this estimation is 0.05 , the correlation coefficient is -0.978 , and the $t-v a l u e$ is -35.9 .

\section{(Insert Figures 6 and 7 About Here)}

\subsection{Estimation of $\alpha_{w}$}

Estimating the Pareto wealth distribution exponent $\alpha_{\mathrm{w}}$ requires data regarding the "right-tail" of the distribution, i.e. data about the wealth of the wealthiest individuals. The French almanac Quid provides wealth data on the top 162,370 individuals in France. This data is in aggregate form, i.e. the numbers of individuals with wealth exceeding certain wealth levels are reported. According to the Pareto Law (eq. (1)), the number of individuals with wealth exceeding a certain level $\mathrm{W}_{\mathrm{x}}$ should be proportional to $\mathrm{W}_{\mathrm{x}}^{-\alpha_{\mathrm{w}}}$ :

$$
\mathrm{N}\left(\mathrm{W}>\mathrm{W}_{\mathrm{x}}\right)=\mathrm{N} \int_{\mathrm{W}_{\mathrm{x}}}^{\infty} \mathrm{f}(\mathrm{W}) \mathrm{dW}=\mathrm{NC} \int_{\mathrm{W}_{\mathrm{x}}}^{\infty} \mathrm{W}^{-\left(1+\alpha_{\mathrm{W}}\right)} \mathrm{dW}=\frac{\mathrm{NC}}{\alpha_{\mathrm{W}}} \mathrm{W}_{\mathrm{x}}^{-\alpha_{\mathrm{W}}}
$$

where $\mathrm{N}\left(\mathrm{W}>\mathrm{W}_{\mathrm{x}}\right)$ is the number of individuals with wealth exceeding $\mathrm{W}_{\mathrm{x}}$, and $\mathrm{N}$ is the total number of individuals. If the Pareto distribution is valid, one expects that

\footnotetext{
${ }^{21}$ It is interesting to note the secondary peak of the empirical distribution at a rate of return of about -0.001. A similar bimodal distribution was observed by Jackwerth and Rubinstein [1996]. We do not have an explanation for this phenomenon in the framework of the present model.
} 
when plotting $\mathrm{N}\left(\mathrm{W}>\mathrm{W}_{\mathrm{x}}\right)$ as a function of $\mathrm{W}_{\mathrm{x}}$ on a double-logarithmic graph, the data points should fall on a straight line with slope $-\alpha_{\mathrm{w}}$. Figure 8 is a double logarithmic plot of $\mathrm{N}\left(\mathrm{W}>\mathrm{W}_{\mathrm{x}}\right)$ as a function of $\mathrm{W}_{\mathrm{x}}$ for the French data provided by Quid. This figure shows an excellent agreement between the empirical wealth distribution and the Pareto-law. In order to estimate $\alpha_{\mathrm{w}}$ for France, we run the regression:

$$
\log \left[\mathrm{N}\left(\mathrm{W}>\mathrm{W}_{\mathrm{x}}\right)\right]_{\mathrm{i}}=\mathrm{A}+\mathrm{B} \log \left[\mathrm{W}_{\mathrm{x}}\right]_{\mathrm{i}}+\varepsilon_{\mathrm{i}}
$$

The absolute value of the slope of the regression line, which is the estimate for $\alpha_{\mathrm{w}}$ is 1.83. $($ Standard error $=0.03$, correlation coefficient $=-0.999 \mathrm{t}$-value $=-59.5)$.

(Insert Figure 8 About Here)

For the U.S and the U.K. the available data regarding the wealthiest people is more detailed but also more limited in scope. For these countries, lists with the ranking and wealth of the several hundreds of wealthiest individuals are published. We use the methods suggested by Levy and Solomon [1997] in order to estimate $\alpha_{\mathrm{w}}$ from these data. A Pareto law distribution of wealth with exponent $\alpha_{\mathrm{w}}$ implies the following relation between the rank of an individual in the wealth hierarchy and her wealth:

$$
\mathrm{W}(\mathrm{n})=\mathrm{An} \mathrm{-}^{-\frac{1}{\alpha_{\mathrm{w}}}},
$$

where $\mathrm{n}$ is the rank (by wealth), and $\mathrm{W}$ is the wealth. The constant $\mathrm{A}$ is given by $\mathrm{A}=\left(\frac{\alpha_{\mathrm{w}}}{\mathrm{NC}}\right)^{-\frac{1}{\alpha_{\mathrm{w}}}}$, where $\mathrm{N}$ is the total number of individuals in the population, and $\mathrm{C}$ is the normalization constant from equation (1); (for a mathematical derivation of this relation see Johnson and Kotz [1970]). 
For the U.S. we obtain data from the 1997 Forbes 400 list. Wealth as a function of rank is plotted in double logarithmic form in Figure 9. Running the regression:

$$
\log [\mathrm{W}(\mathrm{n})]_{\mathrm{i}}=\mathrm{A}+\mathrm{B} \log [\mathrm{n}]_{\mathrm{i}}+\varepsilon_{\mathrm{i}}
$$

we estimate the slope of the regression as -0.74 . This is the estimation of $-1 / \alpha_{w}$, and it corresponds to an estimation of $\alpha_{\mathrm{w}}=1.35$ for the U.S. The standard error of this estimation is 0.005 . We would like to clarify that we do not assume that only the wealthiest 400 individuals determine the S\&P rate of return distribution. Rather, we use the data that we are able to obtain in order to estimate the Pareto constant for the entire upper wealth range. Our estimation of $\alpha_{w}=1.35$ for the U.S., is close to the estimate of $1.35 \leq \alpha_{w} \leq 1.42$ which is obtained by the data provided by Wolff [1996] regarding the percentage of wealth held by the top $1 \%, 5 \%$, and $10 \%$ of the population (see appendix C).

For the U.K. we obtain data from the Sunday Times Rich List 1997. The data are plotted in Figure 10. We obtain a slope of -0.94 which corresponds to a value of $1 / 0.94=1.06$ for $\alpha_{w}$ (standard error 0.004).

The summary of our empirical results appears in Table 1 . This evidence shows a striking agreement between the values of (the a-priory unrelated) $\alpha_{w}$ and $\alpha_{L}$ for the three countries investigated.

Table 1

\begin{tabular}{|l|c|c|}
\hline & $\alpha_{\mathrm{L}}$ & $\alpha_{\mathrm{w}}$ \\
\hline U.S. & $1.37 \pm 0.04$ & $1.35 \pm 0.005$ \\
\hline U.K. & $1.08 \pm 0.03$ & $1.06 \pm 0.004$ \\
\hline France & $1.82 \pm 0.05$ & $1.83 \pm 0.030$ \\
\hline
\end{tabular}


(Insert Figures 9 and 10 About Here)

\section{Concluding Remarks}

The process of wealth accumulation by capital investment is stochastic and multiplicative by nature. This paper shows that homogeneous stochastic processes lead to a Pareto wealth distribution. Thus, the Pareto wealth distribution, and the rather extreme inequality which it implies, is a fundamental and robust outcome of the nature of the capital investment process. Non-homogeneous processes, in which investors have differential investment abilities, lead to a wealth distribution which is different than the Pareto distribution. Thus, the Pareto distribution implies that chance, rather than differential investment ability, is the main source of inequality at the high-wealth range.

The Pareto distribution is closely related to market efficiency. A precise Pareto distribution implies market efficiency. In practice, some degree of market inefficiency can be consistent with the Pareto distribution, in the sense that the resultidistribution cannot be statistically rejected. However, the Pareto distribution does impose a rather tight upper-bound on market inefficiency. The closer the wealth distribution to the Pareto distribution, the smaller the tolerable level of market efficiency.

The Pareto wealth distribution can also explain the (truncated) Lévy distribution of short-term returns, a phenomenon which has puzzled researchers for many years. Our theoretical analysis links between two different research arenas: the distribution of wealth, which is a central issue in economics, and the distribution of stock returns, which plays an important role in finance. The analysis leads to a surprising prediction: the Pareto exponent $\alpha_{\mathrm{w}}$ should be equal to $\alpha_{\mathrm{L}}$, the exponent of the Levy return distribution. Empirical evidence from the U.S., the U.K. and France reveals a striking agreement between these a-priori unrelated parameters (U.S.: $\alpha_{\mathrm{L}}=$ 1.37, $\alpha_{\mathrm{w}}=1.35$; U.K.: $\alpha_{\mathrm{L}}=1.08, \alpha_{\mathrm{w}}=1.06$; France: $\alpha_{\mathrm{L}}=1.82, \alpha_{\mathrm{w}}=1.83$ ). 


\section{References}

Abhyankar, A., Copeland, L. S., and Wong, W., 1995, "Nonlinear Dynamics in Real-Time Equity Market Indices: Evidence From the United Kingdom," The Economic Journal, 105, 864-880.

Aiyagari, S.R., 1994, "Uninsured Idiosyncratic Risk and Aggregate Saving", Quarterly Journal of Economics, 109, 659-84.

Atkinson, A. B., and Harrison A. J., 1978, Distribution of Total Wealth in Britain, Cambridge University Press, Cambridge.

Arnold, B. C., Pareto Distributions, International Co-operative Publishing House, Maryland, 1983.

Auerbach, A.J., and L.J. Kotlikoff, Dynamic Fiscal Policy, New York: Cambridge University Press, 1987.

Belkacem, L., 1996, Processus Stables et Applications á la Finance, Thése de Doctorat, Universitá Paris IX.

Blinder, A. S., Towards an Economic Theory of Income Distribution, The MIT Press, Cambridge, Ma., 1974.

Boissevain, C. H., "Distribution of Abilities Depending on Two or More Independent Factors", Metron, 13, 1939, 49-58.

Boltzmann, L., Lectures on Gas Theory, University of California Press, Berkeley, 1964.

Castaneda, A., Díaz-Giménez, J., and J.V. Ríos-Rull, "Unemployment Spells, Cycllically Moving Factor Shares and Income Distribution Dynamics", Manuscript, Federal Reserve Bank of Minneapolis, 1997.

Champernowne, D. G., 1953, “A Model of Income Distribution”, Economic Journal, 63, 318-351.

Choquet, G., 1960 , "Le theoreme de representation integrale dans les ensembles convees compacts", Ann. Inst. Fourier, 10, 333.

Cont, R., 2001, "Empirical Properties of Asset Returns: Stylized Facts and statistical Issues", Quantitative Finance, 1, 223-236.

Cont, R., Potters, M., and Bouchaud, J. P., 1997, "Scaling in Stock Market Prices: Stable Laws and Beyond." Science and Finance Research Group, Working Paper 97-02.

Davis, H., "The Analysis of Economic Time Series", San Antonio: The Principia Press of Trinity University, 1963, originally as monograph No. 6 of the Cowles Commission for Research in Economics, 1941. 
Díaz-Giménez, J., V. Quadrini, and J.V. Ríos-Rull, 1997, "Dimensions of Inequality: Facts on the U.S. Distributions of Earnings, Income, and Wealth", Quarterly Review of the Federal Reserve Bank of Minneapolis, 21,2, 3-21.

Fama, E. F., 1963(a), "Mandelbrot and the Stable Paretian Hypothesis." Journal of Business, 36, 4 ..

Fama, E. F., 1963(b), "The Distribution of the Daily First Differences of Stock Prices: A Test of Mandelbrot's Stable Paretian Hypothesis", (unpublished doctoral dissertation, University of Chicago).

Fama, E. F., 1965(a), "The Behavior of Stock Prices", Journal of Business, 38, 1, 34-105.

Fama, E. F., 1965(b), "Portfolio Analysis in a Stable Paretian Market", Management Science, 2, 3.

Fama, E. F., and Roll, R., 1968, "Some Properties of Symmetric Stable Distributions", Journal of the American Statistical Association, 63, 817-36.

Fama, E. F., and Roll, R., 1971, "Parameter Estimates for Symmetric Stable Distributions.", Journal of the American Statistical Association, 66, 331-38.

Feller, W., 1971, An Introduction to Probability Theory and its Applications, Vol 2., 2nd edn, Wiley, New York.

Feynman, R. P., Leighton, R.B., and Sands, M., The Feynman Lectures on Physics, vol. 1, Addison Wesley, Reading MA., 1964.

Forbes, 1997, Special 400 List Issue, October 13.

Furstenberg, H. , 1965, Bulletin of the American Mathematical Society, 71, 271-326.

Gabaix, X., 1999, “Zipf's Law for Cities: An Explanation”, Quarterly Journal of Economics, 739-767.

Gnedenko, B. V., and Kolmogorov, A. N., 1954, Limit Distributions for Sums of Independent Variables, Cambridge, Mass.: Addison-Wesley. Ch. 7. (Translated by K. L. Chung).

Gopikrishnan, P., Meyer, M., Amaral, L.A.N, and Stanley, H.E., 1998, "Inverse Cubic Law for the Probability Distribution of Stock Price Variations", European Journal of Physics B, 3, 139-140.

Guillaume, D. M., 1997, "From the Bird's Eye to the Microscope: a Survey of New Stylized Facts of the Intra-day Foreign Exchange Markets", Olsen \& Associates Research Group Working Paper. 
Hausman, J. A., Lo, A. W., and MacKinlay, A. C., 1992, "An Ordered Probit Analysis of Transaction Stock Prices", Journal of Financial Economics, 31 (3), 319-79.

Hsu, D. A., Miller, R. B., and Wichern, D. W., 1974, "On the Stable Paretian Behavior of Stock-Market Prices", Journal of the American Statistical Association, 68, 34.

Huggett, M., 1996, "Wealth Distribution in Life-Cycle Economies", Journal of Monetary Economics, 38, 953-69.

Jackwerth, J. C., and Rubinstein, M., 1996, "Recovering Probability Distributions from Option Prices", Journal of Finance, 51, 5, 1611-32.

Jansen, D.W., and de Vries, C.G., 1991, "On the Frequency of Large Stock Returns: Putting Booms and Busts into Perspective", Review of Economics and statistics, 73, 18-24.

Johnson, N. L., and Kotz, S., 1970, Continuous Univariate distributions - 1, John Wiley and Sons, New York.

Joyce, H. A., Brorsen, W., and Irwin, S. H., 1989, "The Distribution of Futures Prices: A Test of the Stable Paretian and Mixture of Normals Hypotheses", Journal of Financial and Quantitative Analysis, 24, 1.

Kesten, H., "Random Difference Equations and Renewal Theory for Products of Random Matrices", Acta Mathematica, 81, 1973, pp. 207-248.

Krusell, P., and A.A. Smith, 1998, "Income and Wealth Heterogeneity in the Macroeconomy", Journal of Political Economy, 106, 5, 867-896.

Latané H. E., 1959, "Criteria for Choice Among Risky Ventures," Journal of Political Economy, LVII, 144-155.

Leshno, M., and Levy, H., 1997, “Approximately Stochastic Dominance”, Hebrew University Working Paper.

Levy, H., and Markowitz, H. M., 1979, "Approximating Expected Utility by a Function of Mean and Variance", American Economic Review, 69, 3, 308-317.

Lévy P., 1925, Calcul des Probabilitiés, Paris: Gauthier Villars, Part II, ch.6.

Levy, M., and Levy, H., 2001, "Investment Talent and the Pareto Wealth Distribution: Theoretical and experimental Analysis", Hebrew University Working Paper.

Levy, M., and Solomon, S., 1996, "Power Laws are Logarithmic Boltzmann Laws", International Journal of Modern Physics C, 7, 65-72.

Levy, M., and Solomon, S., 1997, "New Evidence for the Power-Law Distribution of Wealth", Physica A. 
Longin, F., 1996, “The Asymptotic Distribution of Extreme Stock Market Returns", Journal of Business, 63, 383-408.

Loomis, L., 1962, "Unique Direct Integral Decompositions on Convex Sets", American Journal of Mathematics, 84, 509-526.

Mandelbrot, B., 1963(a), "The Variation of Certain Speculative Prices.", Journal of Business, 36, 4.

Mandelbrot, B., 1963(b), "New Methods in Statistical Economics", Journal of Political Economy, 61, 421-40.

Mandelbrot, B., 1997, Fractals and Scaling in Finance: Discontinuity, Concentration, and Risk. Springer-Verlag, New York.

Mankiw, N. G., and Zeldes, S. P., 1991, "The Consumption of Stockholders and Nonstockholders." Journal of Financial Economics, 29, 131-35.

Mantegna, R. N., 1991, "Lévy Walks and Enhanced Diffusion in the Milan Stock Exchange." Physica A, 179.

Mantegna, R. N., and Stanley, H. E., 1994, Physics Review Letters, 73, $2946-49$.

Mantegna, R. N., and Stanley, H. E., 1995, "Scaling Behavior in the Dynamics of an Economic Index." Nature, 376, 46-49.

Markowitz, H., 1976, "Investment for the Long Run: New Evidence for an Old Rule", Journal of Finance, 31, 1273-86.

Officer, R. R., 1972, "The Distribution of Stock Returns", Journal of the American Statistical Association, 67, 340.

Pareto, V., 1897, Cours d'Economique Politique, Vol 2. Also, see: Manual of Political Economy, New York: Augustus M. Kelley, 1971, translated from the original 1906 Manuale d'Ecoonomia Politica.

Pareto, V. Manual of Political Economy, New York: Augustus M. Kelley, 1971, translated from the original 1906 Manuale d'Ecoonomia Politica.

Pedrosa, M., and Roll, R., 1998, "Systematic Risk in Corporate Bond Credit Spreads", UCLA Working Paper 7-98.

Persky, J., 1992, "Retrospectives: Pareto's Law," Journal of Economic Perspectives, 6, 181-192.

Pictet, O. V., and Muller, U. A., 1995, "Statistical Study of Foreign Exchange Rates, Empirical Evidence of a Price Change Scaling Law and Intra-day Analysis," Journal of Banking and Finance, 14, pp. 1189-1208. 
Quadrini, V., and J.V. Ríos-Rull, 1997, "Understanding the U.S. Distribution of Wealth", Quarterly Review of the Federal Reserve Bank of Minneapolis, 21,2, 22-36.

QUID, 1998, edited by Fremy, D., RTL, Paris.

Ríos-Rull, J.V., "Models with Heterogeneous Agents", in Frontiers of Business Cycle Research, ed. T.F. Cooley, 98-125, Princeton, N.J., Princeton University Press, 1995.

Roll, R., 1968, "The Efficient Market Model Applied to U.S. Treasury Bill Rates", (unpublished doctoral dissertation, University of Chicago).

Samuelson, P. A., 1967, "Efficient Portfolio Selection for Pareto-Lévy Investments", Journal of Financial and Quantitative Analysis, 2, 2, 107-22.

Samuelson, P. A., 1989, "The Judgment of Economic Science on Rational Portfolio Management: Indexing, Timing, and Long-Horizon Effects", The Journal of Portfolio Management, 4-12.

Scott, D. W., 1992, Multivariate Density Estimation, New York: Wiley.

Simon, H., 1955, "On a Class of Skew distributions", Biometrica, (reprinted in Simon, H., Models of Man, 1957.)

Slottje, D. J., The Structure of Earnings and the Measurement of Income Inequality in the U.S., Elsevier Science Publishers, New York, 1989.

Snyder, C., 1940, Capitalism the Creator, Macmillan.

Stanley, H.E., Amaral, L.A.N., Canning, D., Gopikrishnan, P., Lee, Y., and Liu, Y., 1999, "Econophysics: Can Physicists Contribute to the Science of Economics?", Physica A, 269, 156-169.

Steindl, J., 1965, Random Processes and the Growth of Firms - A Study of the Pareto Law, Charles Griffin \& Company, London.

Sunday Times Rich List 1997, http://www.sunday-times.co.uk/news/pages/resources/ library1.n.html?2286097

Takayasu, H., 1990, Fractals in the Physical Sciences, Wiley.

Teichmoeller, J., 1971, "A Note on the Distribution of Stock Price Changes", Journal of the American Statistical Association, 66.

Wold, H., and Whittle, P., 1957, "A Model Explaining the Pareto Distribution of Wealth", Econometrica, 25, 591-95.

Wolff, E. N., The American Prospect, 22, 1995, 58-64. 
Wolff, E., 1996, "Trends in Household Wealth During 1989-1992." Submitted to the Department of Labor, New York, New York University.

Zajdenweber, D., 1994, "Propriétés Autosimilaires du CAC40." Review d'Economie Politique 104, 408-434.

Zipf, G., Human Behavior and the Principle of Least Effort, Cambridge, MA., Addison-Wesley, 1949. 


\section{Appendix A: Proof of Theorem 3}

\section{Theorem 3:}

If the wealth of investors is distributed according to the Pareto law with exponent $\alpha_{\mathrm{w}}$, and the effect of each investor's trade on the price is stochastically proportional to the investor's wealth, then the resulting price-change (and return) distribution is given by the Lévy distribution with an exponent $\alpha_{\mathrm{L}}=\alpha_{\mathrm{w}}$.

\section{Proof:}

Suppose a single investor is drawn at random to trade with a market maker, and that the effect of the investor on the price is (stochastically) proportional to the investor's wealth. We first prove that in this case a Pareto wealth distribution leads to a Lévy price-change distribution. Then this result is extended to the return distribution, and to the case of a stochastic number of investors trading at each period.

Let us denote the single-trade price change at period $t$ as $\mathrm{Z}_{\mathrm{t}} \cdot \mathrm{Z}_{\mathrm{t}}$ is given by:

$$
\tilde{\mathrm{z}}_{\mathrm{t}}=\tilde{\mathrm{q}}_{\mathrm{t}} \tilde{\mathrm{W}}_{\mathrm{t}},
$$

where $\tilde{\mathrm{W}}_{t}$ is the wealth of the investor randomly chosen to trade at time $t$, and $\tilde{\mathrm{q}}_{t}$ is a stochastic proportionality factor which is uncorrelated with $\tilde{\mathrm{W}}_{t}$, and which is distributed according to some probability density function $\mathrm{h}(\tilde{\mathrm{q}})$. In what follows we derive the distribution for single-trade price changes, and the price change distribution which results from a larger number of trades.

When analyzing the probability of single-trade price changes it is convenient to separate the discussion to the case of positive price changes $(\mathrm{z}>0)$, and negative price changes $(z<0)$. The probability of obtaining a positive single-trade price change which is smaller or equal to a certain value $\mathrm{z}(\mathrm{z}>0)$ is given by: 


$$
G(z)=\int_{-\infty}^{\infty} h(q) F\left(\frac{z}{q}\right) d q, \quad \text { for } z>0
$$

where $\mathrm{G}(\mathrm{z})$ and $\mathrm{F}\left(\frac{\mathrm{z}}{\mathrm{q}}\right)$ are the cumulative distributions of $\tilde{\mathrm{z}}$ and $\tilde{\mathrm{W}}$ respectively.

Thus, the density function of $\mathrm{z}$ is given by:

$$
g(z)=\int_{-\infty}^{\infty} h(q) f\left(\frac{z}{q}\right) \frac{1}{q} d q, \quad \text { for } z>0
$$

Since we are dealing with the case $z>0$, and since the Pareto density function $f(W)$ is non-zero only for $\mathrm{W}>\mathrm{W}_{0}$, the contribution to the integral in eq.(21) is only for values of $\mathrm{q}$ such that $\frac{\mathrm{z}}{\mathrm{q}}>\mathrm{W}_{0}$. Thus, the contribution is non-zero only for $0<\mathrm{q}<\frac{\mathrm{z}}{\mathrm{W}_{0}}$ (if $\mathrm{q}<0$ then $\frac{\mathrm{z}}{\mathrm{q}}<0$ and $\mathrm{f}\left(\frac{\mathrm{z}}{\mathrm{q}}\right)=0$; if $\mathrm{q}>\frac{\mathrm{z}}{\mathrm{W}_{0}}$ then $\frac{\mathrm{z}}{\mathrm{q}}<\mathrm{W}_{0}$ and again $\left.\mathrm{f}\left(\frac{\mathrm{z}}{\mathrm{q}}\right)=0\right)$. Hence, eq.(21) can be written as:

$$
g(z)=\int_{0}^{\frac{z}{W_{0}}} h(q) f\left(\frac{z}{q}\right) \frac{1}{q} d q, \quad \text { for } z>0 .
$$

Similarly, for negative price changes $(z<0)$ we obtain 22 .

$$
g(z)=\int_{\frac{z}{w_{0}}}^{0} h(q) f\left(\frac{z}{q}\right) \frac{-1}{q} d q, \quad \text { for } z<0 .
$$

Combining equations (22) and (23), and employing the Pareto wealth distribution (eq.(1)) for f, we obtain:

\footnotetext{
${ }^{22}$ For $\mathrm{z}<0$ we have $\mathrm{G}(\mathrm{z})=\int_{-\infty}^{\infty} \mathrm{h}(\mathrm{q})\left(1-\mathrm{F}\left(\frac{\mathrm{z}}{\mathrm{q}}\right)\right) \mathrm{dq}$ and therefore $\mathrm{g}(\mathrm{z})=\int_{-\infty}^{\infty} \mathrm{h}(\mathrm{q}) \mathrm{f}\left(\frac{\mathrm{z}}{\mathrm{q}}\right) \frac{-1}{\mathrm{q}} \mathrm{dq}$, and the only non-zero contribution to the integral is for values of $\mathrm{q}$ in the range $\frac{\mathrm{z}}{\mathrm{W}_{0}}<\mathrm{q}<0$.
} 


$$
g(z)=\left\{\begin{array}{cc}
z>0 & z^{-\left(1+\alpha_{W}\right)} C \int_{0}^{\frac{z}{w_{0}}} h(q)\left(\frac{1}{q}\right)^{-\alpha_{w}} d q \\
z<0 & |z|^{-\left(1+\alpha_{w}\right)} C \int_{\frac{z}{w_{0}}}^{0} h(q)\left(-\frac{1}{q}\right)^{-\alpha w} d q
\end{array}\right.
$$

The important property of $\mathrm{g}(\mathrm{z})$ is that it is asymptotically Paretian. Namely,

as $\mathrm{z} \rightarrow \infty \mathrm{g}(\mathrm{z}) \rightarrow \mathrm{D}_{1} \mathrm{z}^{-\left(1+\alpha_{\mathrm{w}}\right)}, \quad$ and as $\mathrm{z} \rightarrow-\infty \mathrm{g}(\mathrm{z}) \rightarrow \mathrm{D}_{2}|\mathrm{z}|^{-\left(1+\alpha_{\mathrm{w}}\right)}$ where $D_{1}$ and $D_{2}$ are given by:

$$
D_{1}=C \int_{0}^{\infty} h(q)\left(\frac{1}{q}\right)^{-\alpha_{w}} d q, \quad D_{2}=C \int_{-\infty}^{0} h(q)\left(-\frac{1}{q}\right)^{-\alpha_{w}} d q
$$

(Asymptotically Paretian distributions are distributions that have power-law "tails", see, for example, Fama [1963a] p. 423).

Thus, the single-trade price change distribution generated by a market in which investors' wealth is distributed according to the Pareto law with exponent $\alpha_{\mathrm{w}}$ is asymptotically Paretian with the same exponent $\alpha_{\mathrm{w}}$. The price change after $n$ single trades is simply the sum of these single-trade price changes. The Doblin-Gnedenko result states that the sum of many i.i.d random variables which are asymptotically paretian with some exponent $\alpha$ converges to a Lévy distribution with characteristic exponent $\alpha$ (Gnedenko and Kolmogorov [1954], Fama [1963], Feller [1971]). Thus, the distribution of the total price change, which is the sum of many single-trade price changes, converges to the Lévy distribution. Moreover, since the single-trade price changes are asymptotically Paretian with the same exponent as the Pareto-law wealth exponent $\alpha_{\mathrm{w}}$, by the Doblin-Gnedenko result the price-change Lévy distribution will be characterized by the same exponent, i.e. $\alpha_{L}=\alpha_{w}$. Q.E.D. 
Similar considerations to those discussed in Theorem 3 lead to a Lévy distribution with $\alpha_{L}=\alpha_{W}$ for rates of return and for log-returns as well for price changes. If the price remains at a fairly constant level during the sample period, it is straightforward that a Lévy price-change distribution implies a Lévy rate of return distribution: since the rate of return is just the price change divided by the price, if the price level is fairly constant, the rate of return is just the price change divided by an (almost) constant number, and therefore if price changes are distributed according to the Lévy distribution, so are rates of return. This result can also be extended to the case where the price does change considerably over the sample period, if one also takes into account the effect of the price level on the average wealth.

\section{Extension: Variable Trading Frequency}

In the preceding Theorem 3 we have assumed that at time period $t$ only one investor is chosen to trade with the market-maker. This assumption can be relaxed to allow for a stochastic number of investors to trade at each time period. The stochastic price change due to the effect of a single trade is given by:

$$
\tilde{\mathrm{z}}=\tilde{\mathrm{q}} \mathrm{W}
$$

In Theorem 3 it was shown that $\mathrm{g}(\mathrm{z})$, the probability density function of $\mathrm{z}$, is asymptotically Paretian with exponent $\alpha_{\mathrm{w}}$. Let us denote the sum of $\mathrm{m}$ i.i.d. random variables $z$ by $S_{m}: S_{m} \equiv z^{1}+z^{2}+\ldots+z^{m}$. Notice that because the z's are asymptotically Paretian with exponent $\alpha_{\mathrm{w}}$, so is their sum $S_{\mathrm{m}}$ (Gnedenko and Kolmogorov [1954]). Let us denote the density function of $\mathrm{S}_{\mathrm{m}}$ by $\mathrm{k}_{\mathrm{m}}$. The number of trades taking place at a given time period is a discrete random variable which we denote by $\tilde{\mathrm{m}}$ : 


$$
\tilde{\mathrm{m}}=\left\{\begin{array}{lc}
1, & \text { probability } \\
2, & \pi_{1} \\
\vdots & \pi_{2} \\
\mathrm{~m}, & \pi_{\mathrm{m}} \\
\vdots & \vdots
\end{array}\right.
$$

The probability density function of an aggregate price change $z_{t}$ at time period $t$ is given by:

$$
\mathrm{g}\left(\mathrm{z}_{\mathrm{t}}\right)=\sum_{\mathrm{m}=1}^{\infty} \pi_{\mathrm{m}} \mathrm{k}_{\mathrm{m}}\left(\mathrm{z}_{\mathrm{t}}\right)
$$

where $\mathrm{m}$ is the number of trades, $\mathrm{k}_{\mathrm{m}}\left(\mathrm{z}_{\mathrm{t}}\right)$ is the density function of $\mathrm{S}_{\mathrm{m}}$ at $\mathrm{z}_{\mathrm{t}}$, and the summation is over all possible numbers of trades in a single time period. As the $\mathrm{k}_{\mathrm{m}}$ 's are asymptotically Paretian distributions with an exponent $\alpha_{\mathrm{w}}$, so is $\mathrm{g}\left(\mathrm{z}_{\mathrm{t}}\right)$, their weighted average. (To see this note that if $\mathrm{k}_{\mathrm{i}}\left(\mathrm{z}_{\mathrm{t}}\right) \rightarrow \mathrm{d}_{\mathrm{i}} \mathrm{z}_{\mathrm{t}}^{-\left(1+\alpha_{\mathrm{w}}\right)}$ as $\mathrm{z}_{\mathrm{t}} \rightarrow \infty$, and $\mathrm{k}_{\mathrm{j}}\left(\mathrm{z}_{\mathrm{t}}\right) \rightarrow \mathrm{d}_{\mathrm{j}} \mathrm{z}_{\mathrm{t}}^{-\left(1+\alpha_{\mathrm{w}}\right)}$ as $\mathrm{z}_{\mathrm{t}} \rightarrow \infty$, then $\pi_{\mathrm{i}} \mathrm{k}_{\mathrm{i}}\left(\mathrm{z}_{\mathrm{t}}\right)+\pi_{\mathrm{j}} \mathrm{k}_{\mathrm{j}}\left(\mathrm{z}_{\mathrm{t}}\right) \longrightarrow\left(\pi_{\mathrm{i}} \mathrm{d}_{\mathrm{i}}+\pi_{\mathrm{j}} \mathrm{d}_{\mathrm{j}}\right) \mathrm{z}_{\mathrm{t}}^{-\left(1+\alpha_{\mathrm{w}}\right)}$ as $\mathrm{z}_{\mathrm{t}} \rightarrow \infty$, which implies that the weighted average is also asymptotically Paretian). As the $\mathrm{z}_{\mathrm{t}}$ 's have been shown to be asymptotically Paretian with exponent $\alpha_{\mathrm{w}}$ even if the number of trades per period is stochastic, according to the Doblin-Gnedenko result, for a large number of trades, the price-change distribution converges to the Lévy distribution with the same exponent $\alpha_{\mathrm{w}}$, which is the Pareto constant of the wealth distribution. Thus, the result of the model is robust to a stochastic number of trades at each time period. 


\section{Appendix B: Derivation of the Lévy Probability Density Function at 0}

Denote the value of the Lévy p.d.f at 0 by $\mathrm{p}_{0}$.

Lemma:

$$
\mathrm{p}_{0} \equiv \mathrm{L}_{\alpha_{\mathrm{L}}}^{\gamma}(0)=\frac{\Gamma\left(1 / \alpha_{\mathrm{L}}\right)}{\pi \alpha_{\mathrm{L}}(\gamma \Delta \mathrm{t})^{1 / \alpha_{\mathrm{L}}}}
$$

Proof:

From the definition of $L_{\alpha L}^{\gamma}(x)$ in equation (12):

$\mathrm{L}_{\alpha_{\mathrm{L}}}^{\gamma}(0)=\frac{1}{\pi} \int_{0}^{\infty} \exp \left(-\gamma \Delta \mathrm{t} \mathrm{q}^{\alpha_{\mathrm{L}}}\right) \cos (\mathrm{q} \times 0) \mathrm{dq}=\frac{1}{\pi} \int_{0}^{\infty} \exp \left(-\gamma \Delta \mathrm{t} \mathrm{q}^{\alpha_{\mathrm{L}}}\right) \mathrm{dq}$

Define a new variable $u=\gamma \Delta \mathrm{tq}^{\alpha_{\mathrm{L}}}$, and note that $\mathrm{dq}=\alpha_{\mathrm{L}}^{-1}(\gamma \Delta \mathrm{t})^{-\frac{1}{\alpha_{\mathrm{L}}}} \mathbf{u}^{\left(\frac{1}{\alpha_{\mathrm{L}}}-1\right)} \mathrm{du}$.

Substituting in equation (28) we obtain:

$$
\mathrm{L}_{\alpha_{\mathrm{L}}}^{\gamma}(0)=\frac{1}{\left.\pi \alpha_{\mathrm{L}}(\gamma \Delta \mathrm{t})\right)_{\alpha_{\mathrm{L}}}^{\frac{1}{2}}} \int_{0}^{\infty} \exp (-\mathrm{u}) \mathrm{u}^{\left(\frac{1}{\alpha_{\mathrm{L}}}-1\right)} \mathrm{du} .
$$

Recalling that the integral is the definition of $\Gamma\left(\frac{1}{\alpha \mathrm{L}}\right)$ we have:

$$
L_{\alpha_{L}}^{\gamma}(0)=\frac{\Gamma\left(1 / \alpha_{L}\right)}{\pi \alpha_{L}(\gamma \Delta t)^{1 / \alpha_{L}}}
$$




\section{Appendix C: Alternative Estimate of the Pareto Constant $\alpha_{w}$ for the U.S.}

Wolff's [1996] findings regarding the holdings of the top 1\%, top 5\%, and top 10\% of the U.S. population in 1992 are reported in Table II below:

\section{Table 2}

\begin{tabular}{|c|c|}
\hline $\mathrm{k}$ & $\mathrm{P}_{\mathrm{k}}$ \\
\hline $1 \%$ & $37.2 \%$ \\
\hline $5 \%$ & $60.0 \%$ \\
\hline $10 \%$ & $71.8 \%$ \\
\hline
\end{tabular}

In this table $\mathrm{P}_{\mathrm{k}}$ denotes the percentage of total wealth held by the top $\mathrm{k}$ percent of the population. A Praeto-law wealth distribution with exponent $\alpha_{\mathrm{w}}$ implies the following relationship for any two k's:

$$
\frac{\mathrm{P}_{\mathrm{k}_{1}}}{\mathrm{P}_{\mathrm{k}_{2}}}=\left(\frac{\mathrm{k}_{1}}{\mathrm{k}_{2}}\right)^{1-\frac{1}{\alpha_{\mathrm{w}}}}
$$

(See proof below). Employing this relationship we can estimate $\alpha_{\mathrm{w}}$ for the U.S. by using the data in Table II. By comparing the holdings of the top $1 \%$ with the holdings of the top $5 \%$ we obtain:

$$
\frac{0.372}{0.600}=\left(\frac{0.01}{0.05}\right)^{1-\frac{1}{\alpha_{w}}}
$$

which yields $\alpha_{\mathrm{w}}=1.42$. A similar comparison of the holdings of the top $1 \%$ with the holdings of the top $10 \%$ yields $\alpha_{\mathrm{w}}=1.42$. Comparing the holdings of the top $5 \%$ with the holdings of the top $10 \%$ yields $\alpha_{w}=1.35$. 


\section{Lemma:}

A Praeto-law wealth distribution with exponent $\alpha_{w}$ implies the following relationship for any two k's:

$$
\frac{\mathrm{P}_{\mathrm{k}_{1}}}{\mathrm{P}_{\mathrm{k}_{2}}}=\left(\frac{\mathrm{k}_{1}}{\mathrm{k}_{2}}\right)^{1-\frac{1}{\alpha_{\mathrm{w}}}}
$$

$\underline{\text { Proof: }}$

Assuming the Pareto-law (eq.(1)), the number of individuals with wealth exceeding $\mathrm{W}$ is given by:

$$
\mathrm{n}(\mathrm{W})=\mathrm{N} \int_{\mathrm{w}}^{\infty} \mathrm{f}(\mathrm{x}) \mathrm{dx}=\mathrm{NC} \int_{\mathrm{W}}^{\infty} \mathrm{x}^{-\left(1+\alpha_{\mathrm{w}}\right)}=\frac{\mathrm{NC}}{\alpha_{\mathrm{w}}} \mathrm{W}^{-\alpha_{\mathrm{w}}},
$$

where $\mathrm{N}$ is the total number of individuals. This number of individuals corresponds to a proportion $\mathrm{k}=\frac{\mathrm{n}(\mathrm{W})}{\mathrm{N}}=\frac{\mathrm{C}}{\alpha_{\mathrm{w}}} \mathrm{W}_{\mathrm{k}}^{-\alpha_{\mathrm{w}}}$ of the population. The above result can be restated in the following way: the wealth of the poorest individual in the top $\mathrm{k} \%$ of the population is given by:

$$
\mathrm{W}_{\mathrm{k}}=\left(\frac{\mathrm{k} \alpha_{\mathrm{w}}}{\mathrm{C}}\right)^{-\frac{1}{\alpha_{\mathrm{w}}}}
$$

(where $\mathrm{k}$ is expressed as a proportion, i.e. $0 \leq \mathrm{k} \leq 1$ ). The aggregate wealth held by the top $\mathrm{k} \%$ of the population is given by:

$$
\mathrm{N} \int_{\mathrm{W}_{\mathrm{k}}}^{\infty} \mathrm{f}(\mathrm{W}) \mathrm{WdW}=\mathrm{NC} \int_{\mathrm{W}_{\mathrm{k}}}^{\infty} \mathrm{W}^{-\left(1+\alpha_{\mathrm{w}}\right)} \mathrm{WdW}=\frac{\mathrm{NC}}{\alpha_{\mathrm{W}}-1} \mathrm{~W}_{\mathrm{k}}^{1-\alpha_{\mathrm{W}}}=\left(\frac{\mathrm{NC}^{\frac{1}{\alpha_{\mathrm{W}}}}}{\alpha_{\mathrm{W}}-1}\right) \alpha_{\mathrm{w}}^{\left(1-\frac{1}{\alpha_{\mathrm{w}}}\right)} \mathrm{k}^{\left(1-\frac{1}{\alpha_{\mathrm{W}}}\right)},
$$

where the last equality is obtained by substituting $\mathrm{W}_{\mathrm{k}}$ from equation (33). 
The percentage of wealth held by the top $\mathrm{k} \%$ of the population is:

$$
\mathrm{P}_{\mathrm{k}}=\frac{1}{\mathrm{~W}_{\text {total }}}\left(\frac{\mathrm{NC}^{\frac{1}{\alpha_{\mathrm{w}}}}}{\alpha_{\mathrm{W}}-1}\right) \alpha_{\mathrm{w}}^{\left(1-\frac{1}{\alpha_{\mathrm{w}}}\right)} \mathrm{k}^{\left(1-\frac{1}{\alpha_{\mathrm{w}}}\right)}
$$

where $\mathrm{W}_{\text {total }}$ is the total wealth of all the population. Comparing the percentage of wealth held by the top $\mathrm{k}_{1} \%$ of the population, with the percentage of wealth held by the top $\mathrm{k}_{2} \%$ of the population, we obtain:

$$
\frac{\mathrm{P}_{\mathrm{k}_{1}}}{\mathrm{P}_{\mathrm{k}_{2}}}=\left(\frac{\mathrm{k}_{1}}{\mathrm{k}_{2}}\right)^{1-\frac{1}{\alpha_{\mathrm{W}}}}
$$

Note: In the above proof we have assumed that the Pareto wealth distribution holds for all wealth levels. However, it is straightforward to show that the above result is also valid if one assumes a Pareto distribution in the high wealth range but a different wealth distribution in the low wealth range (as long as the k's are in the high wealth range, in which the Pareto wealth distribution holds). 
$1 \mathrm{a}$

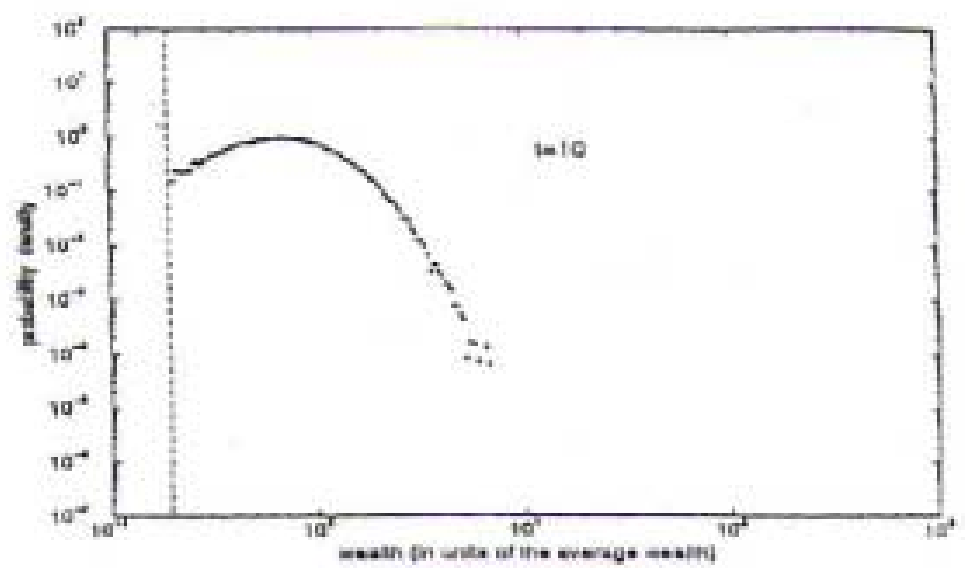

$1 b$

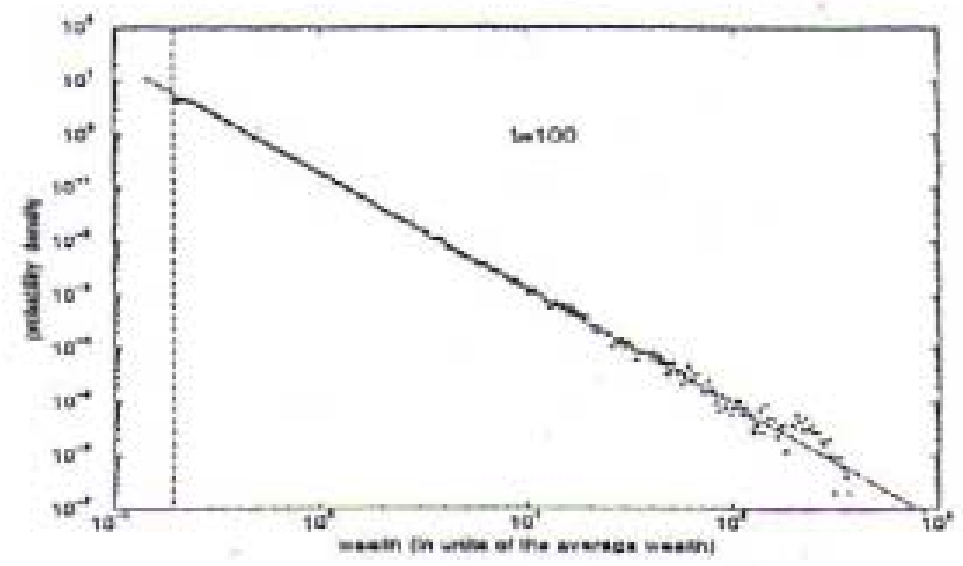

$1 c$

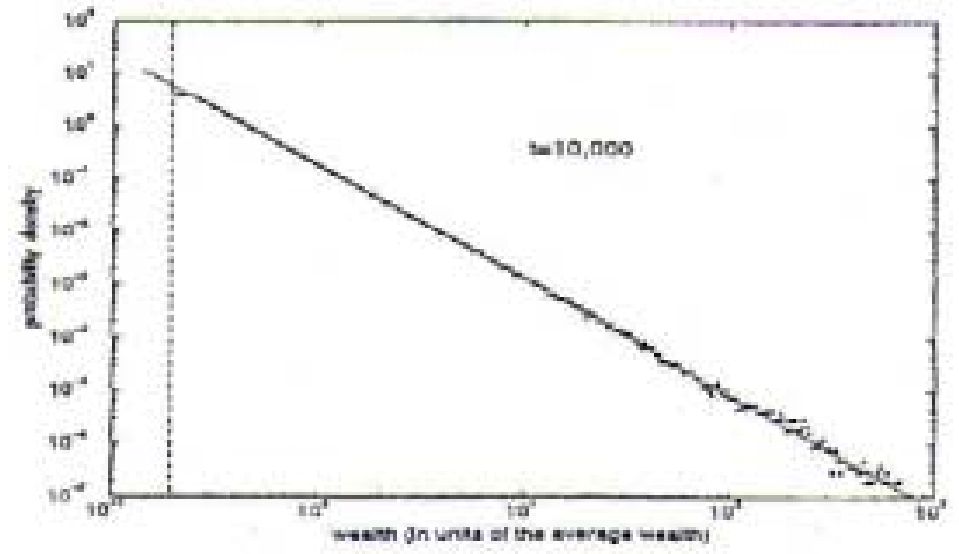

Figure 1: The evolution of the wealth distribution in a simulation of a stochastic multiplicative process. Initially all investors have the same wealth. 1a. After $t=10$ time steps the distribution is still centered around the average wealth. 1b. After $t=100$ time steps the Pareta distribution (straight line on the double-logarithmic scalo) is obtained. 1c. From that time onwards, the Pareto distribution remains as the steady state. 


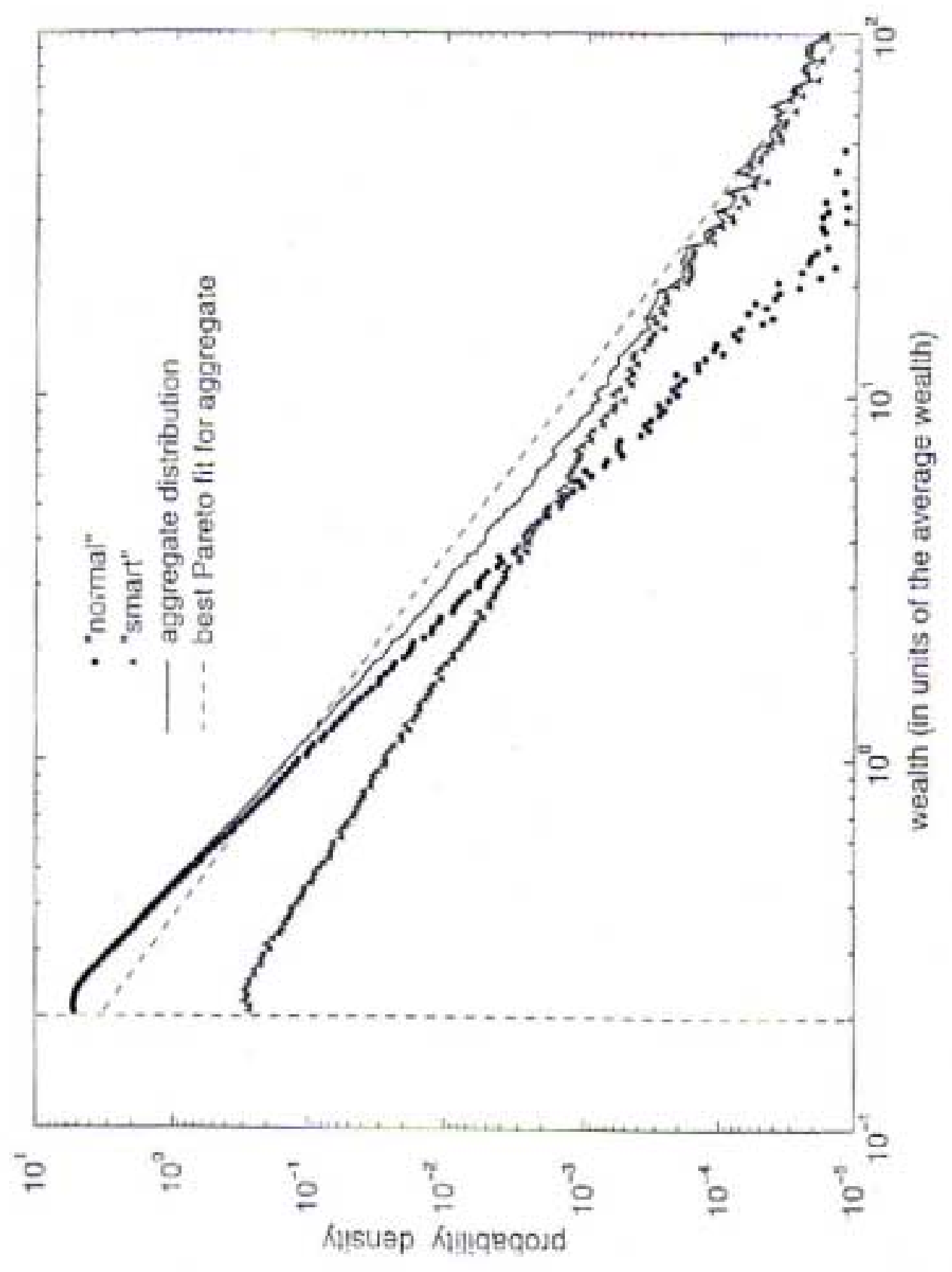

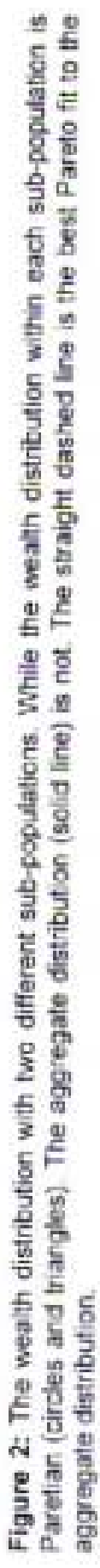




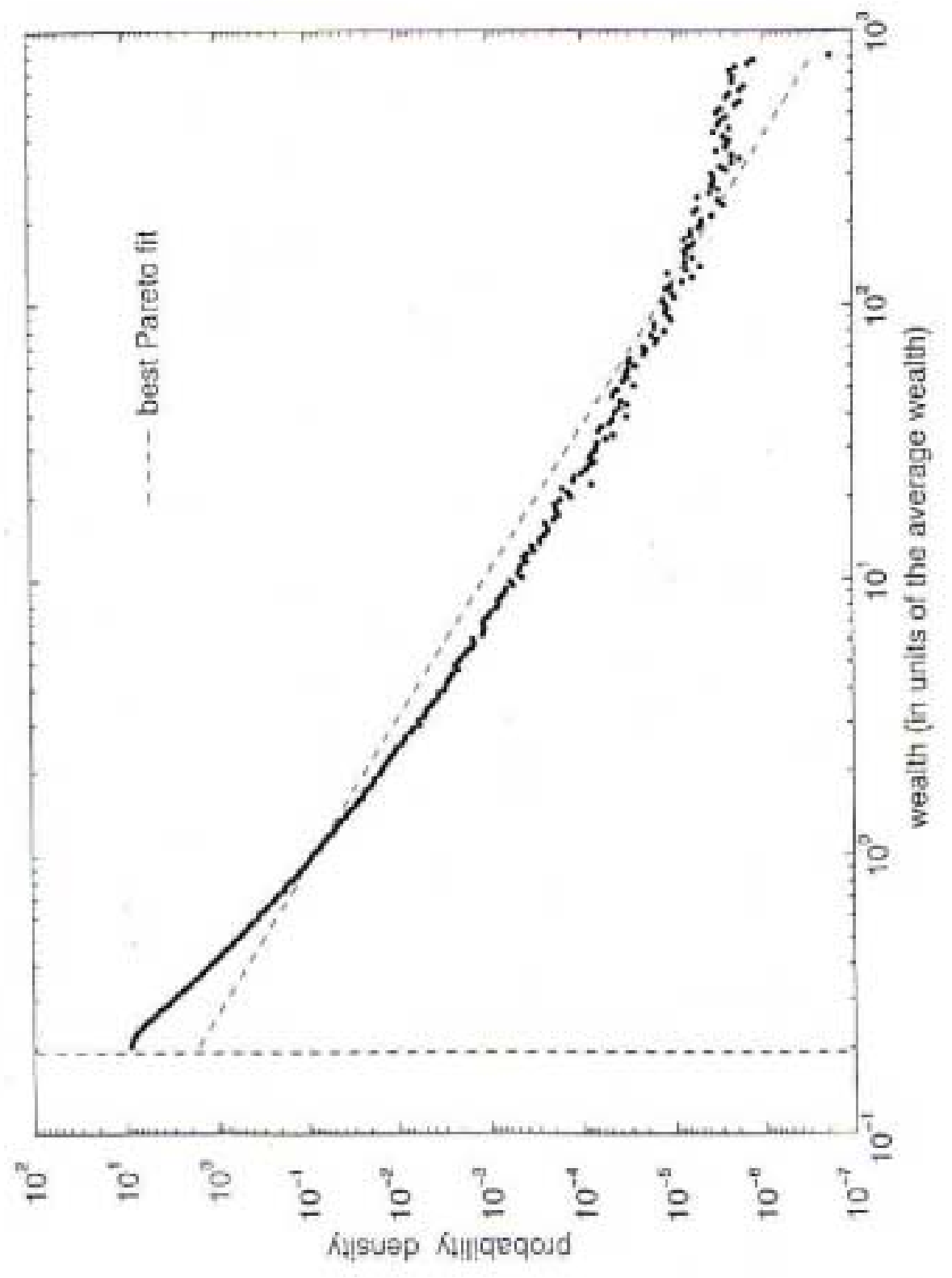

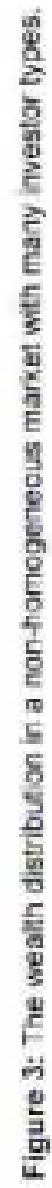




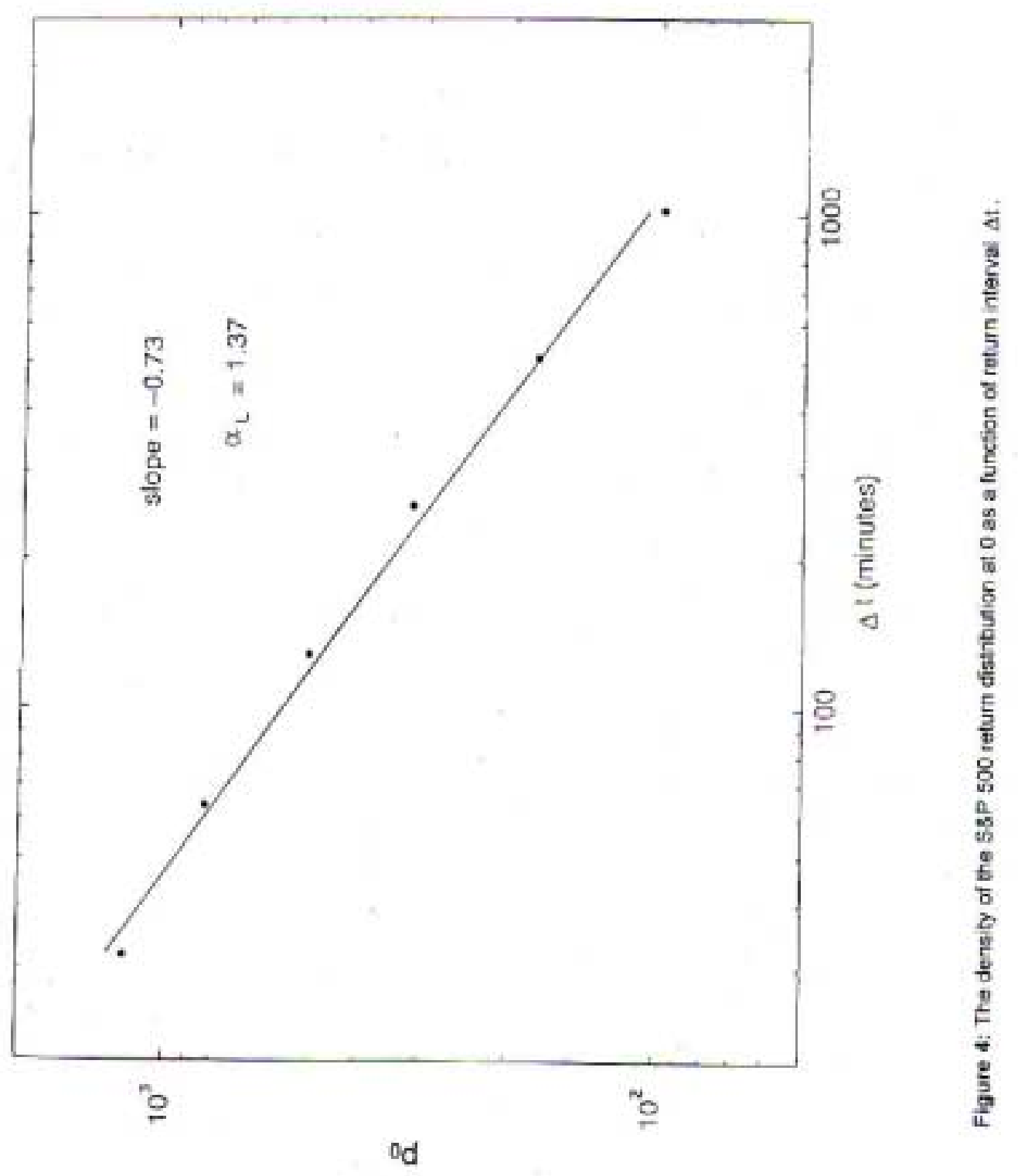




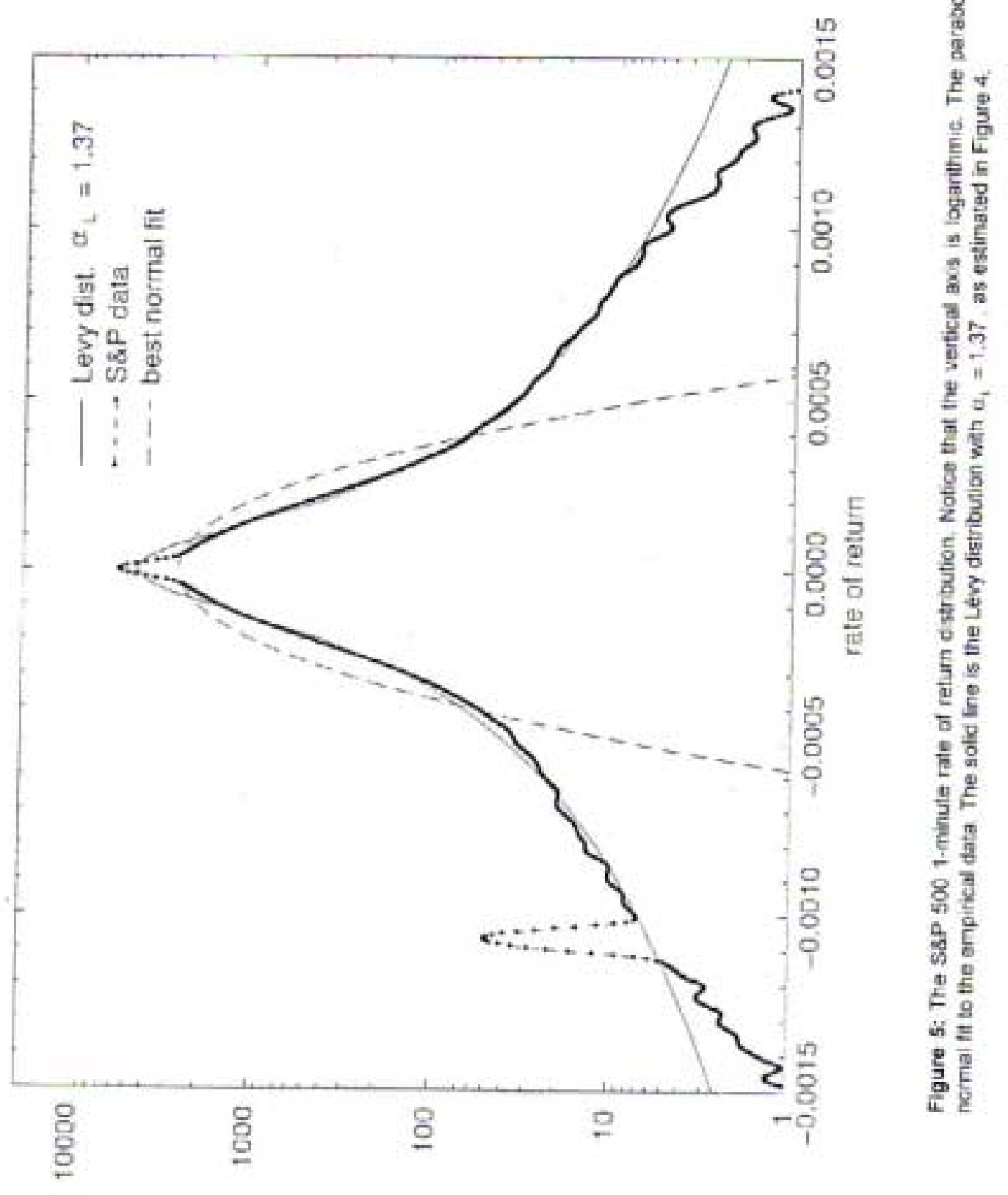




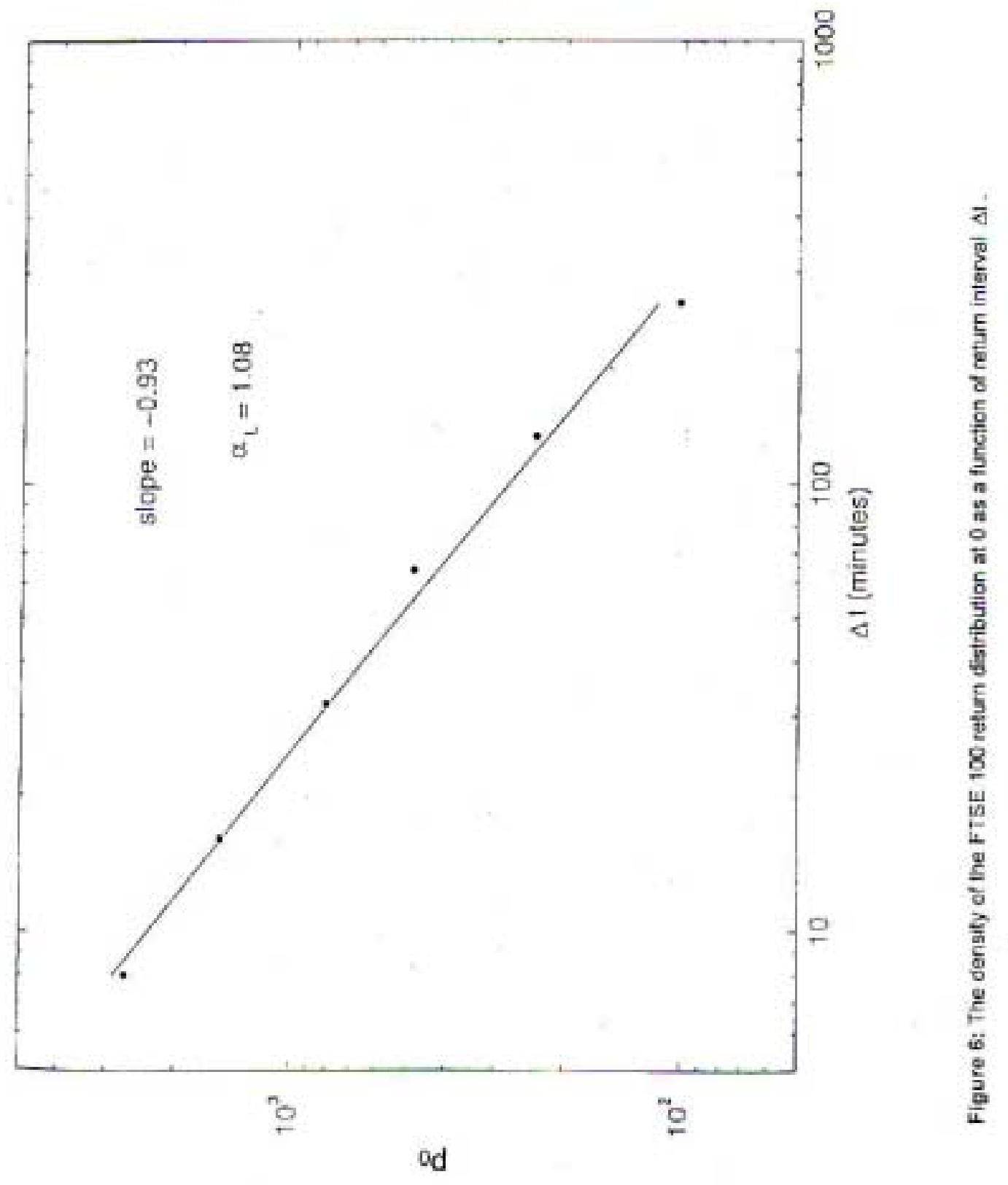




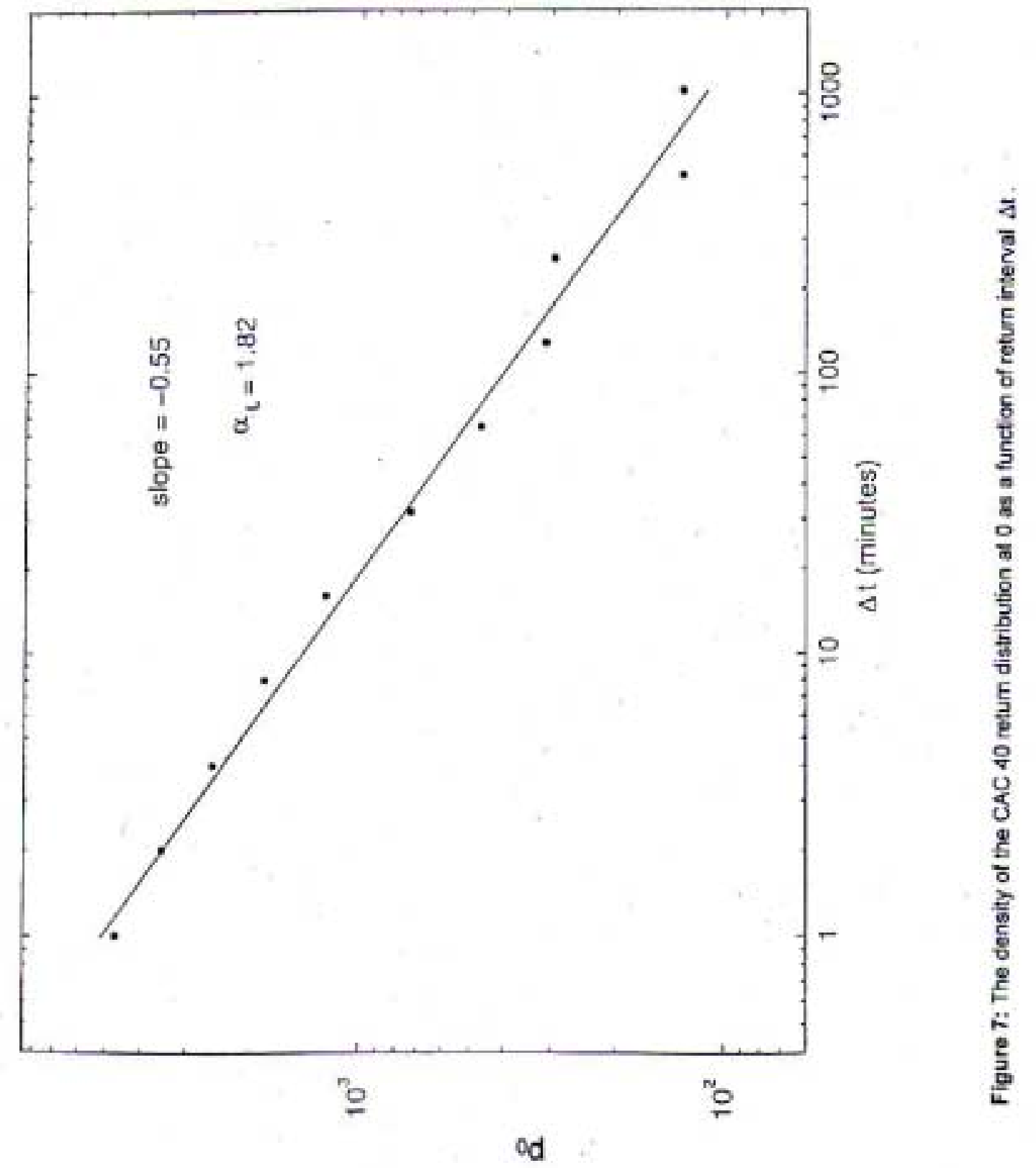




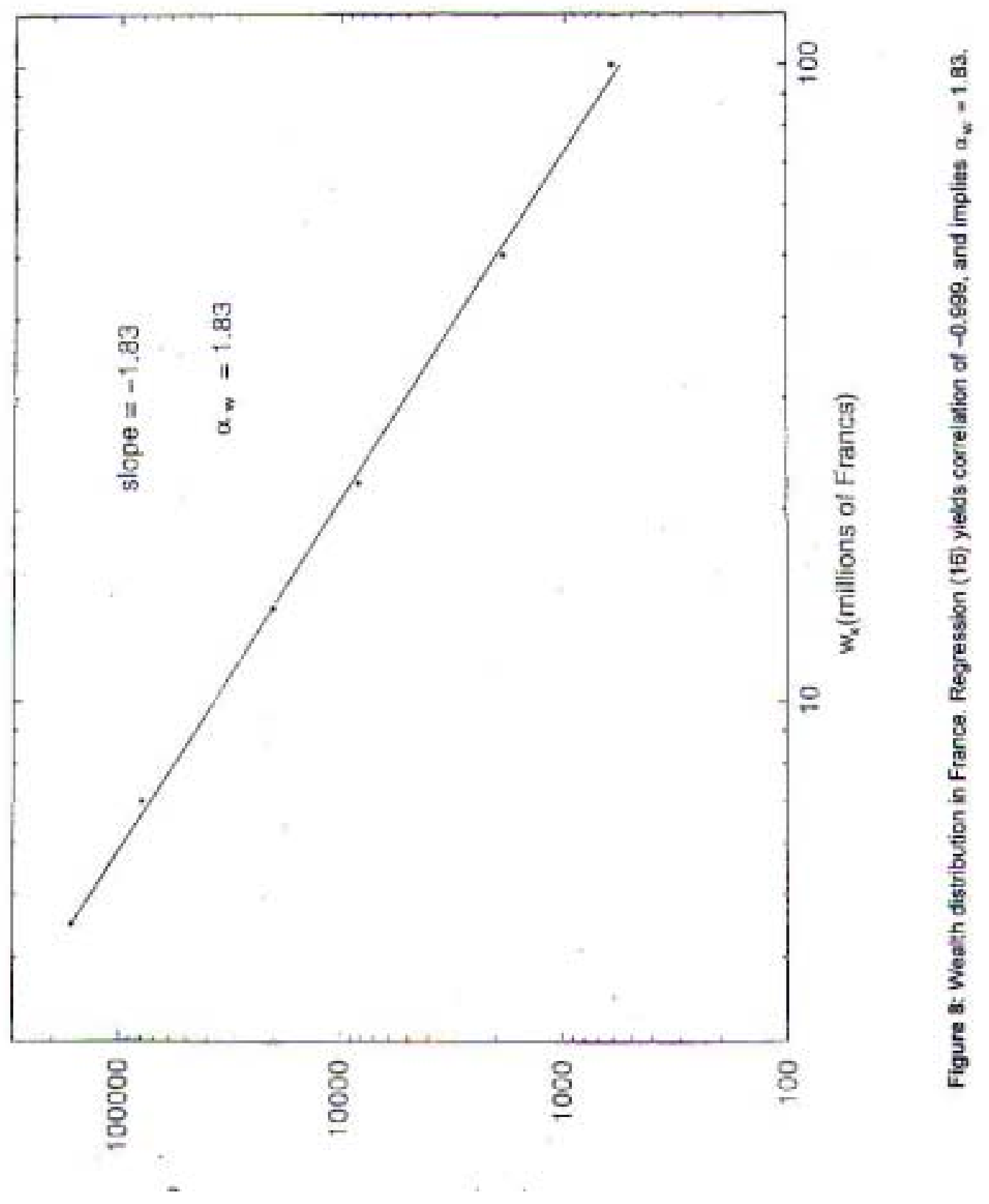




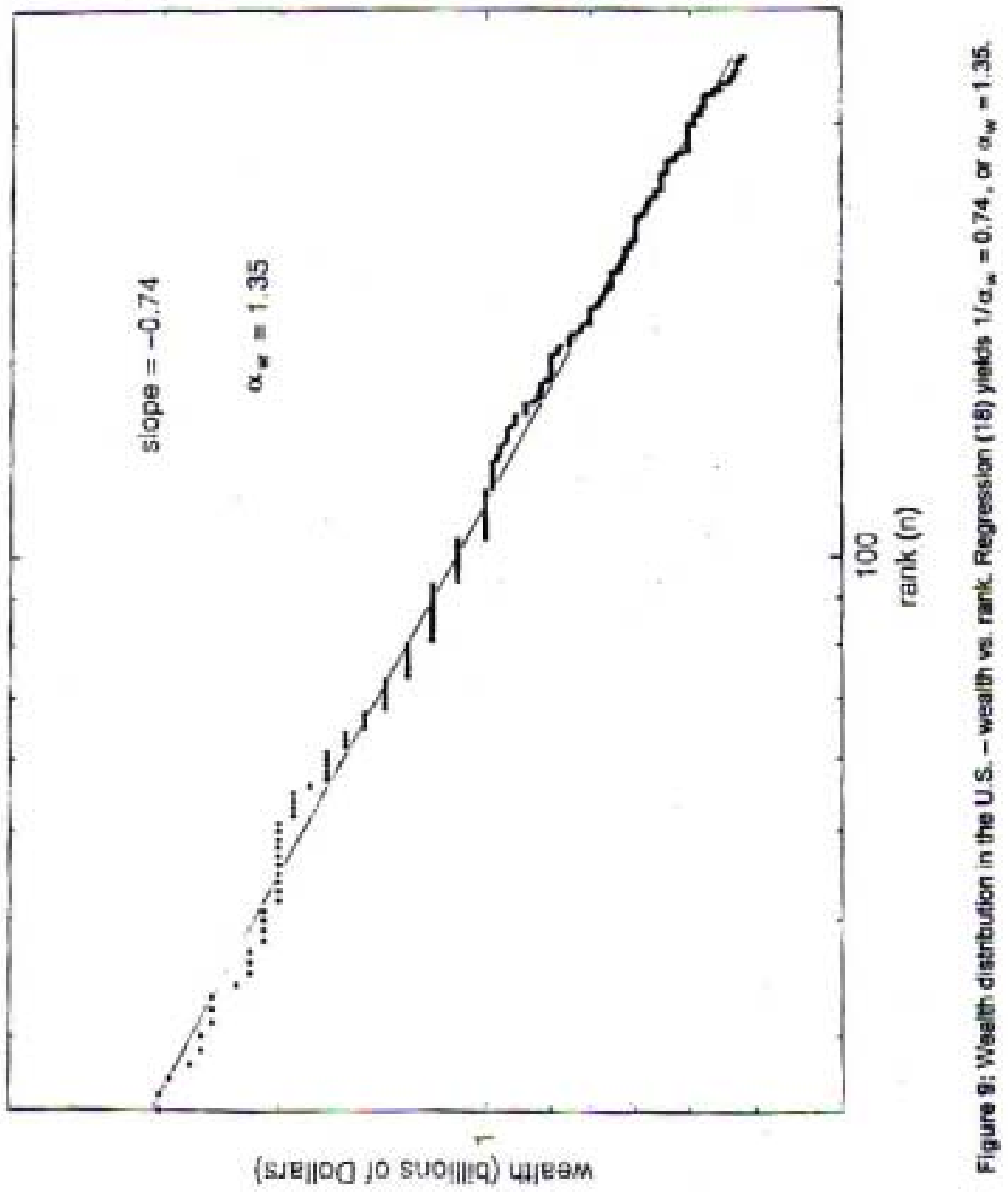




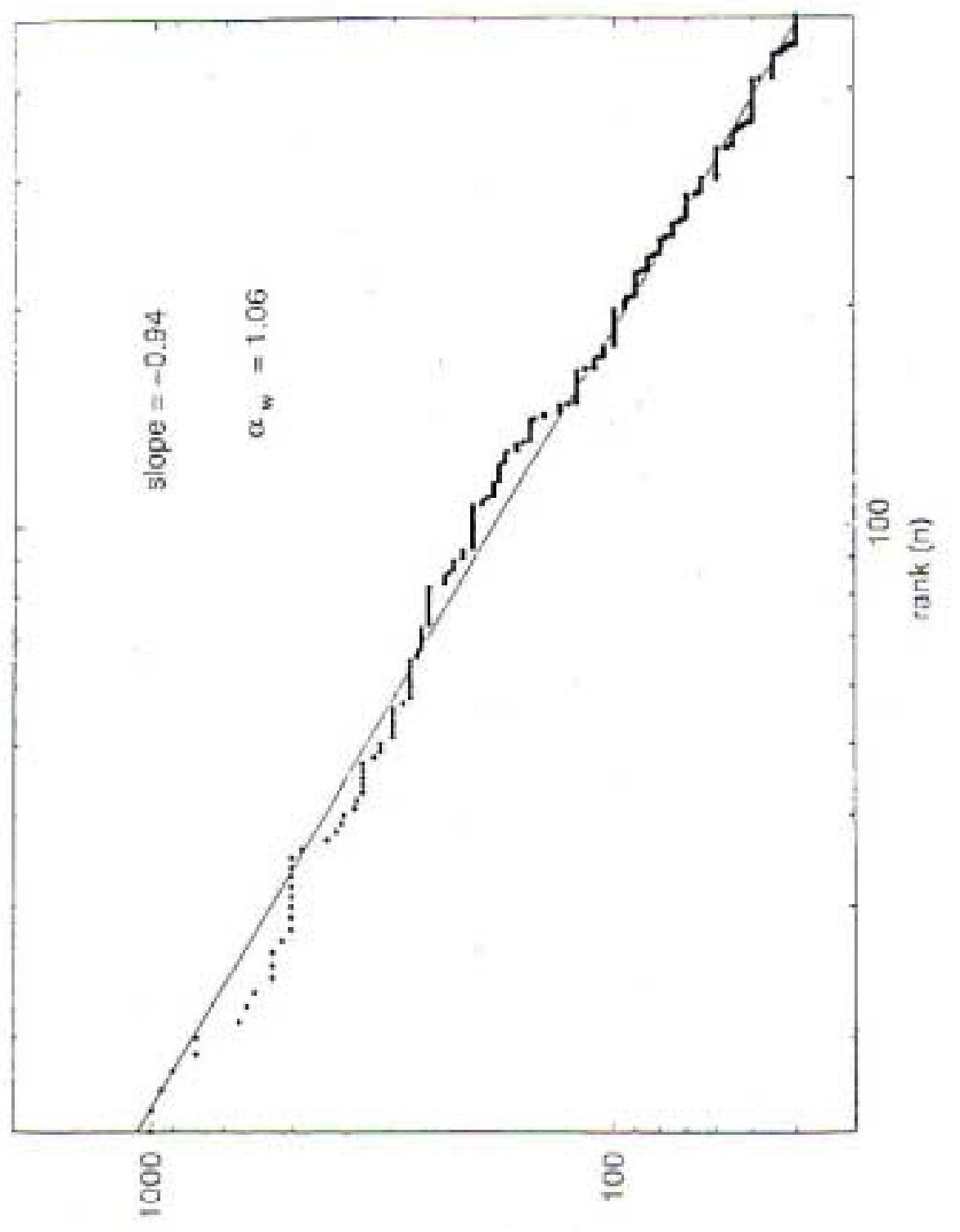

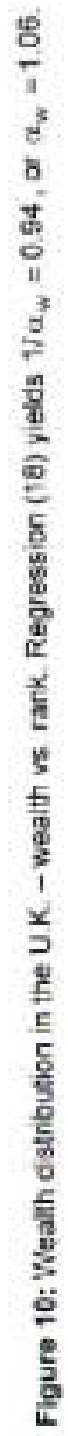

(spunod to suoiniu) чырем 